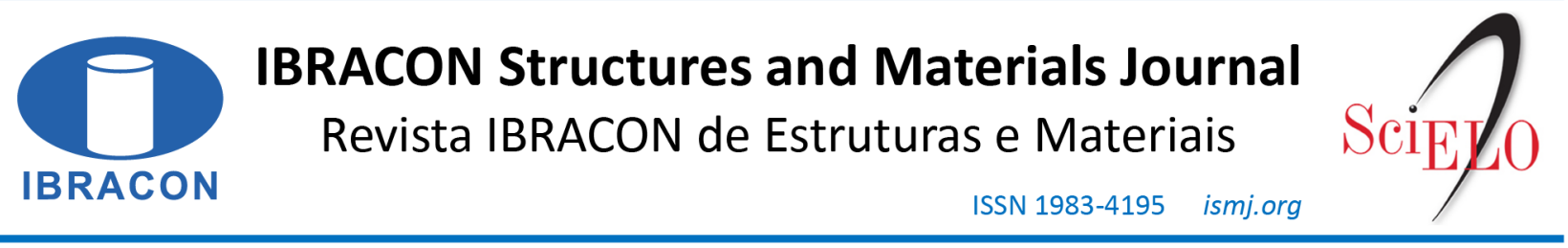

ORIGINAL ARTICLE

\title{
Three-dimensional modelling of wall-beam interaction in structural masonry buildings
}

\section{Modelagem tridimensional da interação parede-viga em edifícios de alvenaria estrutural}

\author{
Anna Christinna Secundo Lopes ${ }^{\mathrm{a}}$ \\ Joel Araújo do Nascimento Neto ${ }^{\mathrm{a}}$ \\ Klaus André de Sousa Medeiros ${ }^{\mathrm{b}}$ \\ Daniel Nelson Maciel ${ }^{\mathrm{a}}$ (D)
}

\begin{abstract}
${ }^{a}$ Universidade Federal do Rio Grande do Norte - UFRN, Programa de Pós-graduação em Engenharia Civil, Natal, RN, Brasil
${ }^{b}$ Universidade Federal Rural do Semi-Árido - UFERSA, Departamento de Engenharias, Angicos, RN, Brasil
\end{abstract}

Received 17 September 2018 Accepted 05 March 2020

\begin{abstract}
Wall-beam interaction (wall-beam system) is a phenomenon that requires further investigation in order to be consistently incorporated into structural building analysis. Researchers such as Wood, Rosenhaupt, Burhouse, Stafford Smith, Navaratnarajah, Davies, Riddington and Armed conducted tests on specimens to develop simplified analysis models, emphasizing the behavior of walls without openings under one span beams. The present study performed computational analysis using an specific equivalent frame model in order to study the behavior of the wall-beam system in more complex wall and beam arrangements. The examples considered the linear elastic behavior of materials and consisted of assessing stress distribution and displacements on support beams, in addition to stresses at the bottom of the walls, for panels in a real structural masonry building. Two- and three-dimensional analyses were used and the results showed the importance of three-dimensional analysis of wall interconnections. The effects of eccentricity between the vertical plane of the wall and horizontal support beam axis were also evaluated, showing the strong influence of twisting moments in support beam design
\end{abstract}

Keywords: structural masonry, wall-beam composite behavior, computational modeling, equivalent frame, wall-beam eccentricity.

Resumo: A interação entre paredes estruturais e vigas de transição (sistema parede-viga) é um fenômeno que ainda carece de estudos para se realizar sua consideração de forma sistemática na análise de edifícios. No passado, pesquisadores como Wood, Rosenhaupt, Burhouse, Stafford Smith, Navaratnarajah, Davies, Riddington e Armed, realizaram experimentos e buscaram desenvolver modelos de cálculo simplificados para representar esse fenômeno. Entretanto, os estudos se limitaram ao caso de vigas biapoidas e paredes sem aberturas. O estudo apresentado neste artigo teve como objetivo realizar análises por meio de modelagem computacional do sistema parede-viga em situações mais complexas de comportamento, empregando-se um específico modelo de barras equivalentes. Os exemplos elaborados consideraram comportamento elástico linear para os materiais e consistiram na avaliação dos esforços e deslocamentos verticais nas vigas de apoio, além das tensões na base das paredes, para painéis de um edifício real de alvenaria estrutural. A modelagem computacional foi elaborada segundo abordagens bidimensionais e tridimensionais da estrutura. Dentre os resultados obtidos, destaca-se a importância da consideração do efeito das amarrações entre painéis de alvenaria via modelo tridimensional devido à intensa redistribuição de esforços verificada. Também foi realizada a análise de uma possível excentricidade no sistema parede-viga, o que permitiu verificar que a consideração dos momentos de torção influenciou consideravelmente no dimensionamento das vigas de suporte.

Palavras-chave: alvenaria estrutural, interação parede-viga, modelagem computacional, modelo de barras equivalentes, excentricidade parede-viga.

How to cite: A. C. S. Lopes, J. A. Nascimento Neto, K. A. S. Medeiros, and D. N. Maciel, "Three-dimensional modelling of wall-beam interaction in structural masonry buildings," Rev. IBRACON Estrut. Mater., vol. 13, no. 4, e13414, 2020, https://doi.org/10.1590/S1983-41952020000400014 


\section{INTRODUCTION}

Although structural masonry is a widely used system in the Brazilian construction industry, new studies are needed to enhance knowledge of its structural behavior. One example is the interaction between masonry walls and the corresponding support structures, where there is a need to develop simple and consistent calculation models to determine internal forces and stresses. In addition, designing taller buildings, making architecture layouts more flexible and the use of subsoils and ground floors as common areas for residents highlight the need for support structures, thereby justifying in-depth studies on wall-beam interaction, also known as the arching effect.

The arch effect, or flow stress arching inside structural walls, is only one of the aspects for engineers to assess. Thus, for the purposes of this study, the authors preferred to refer to this phenomenon as wall-beam interaction or wall-beam system.

According to Barbosa [1], interaction changes the distribution of wall stresses and support beam forces that must be considered in the design. The transfer of vertical loads from a masonry wall to its foundations depends on the type of support. Walls can be supported by strip footings, or simply supported such as regularly spaced pilotis or foundation piles. Walls on strip footings exhibit nearly uniform distribution at the bottom, causing small direct load transfers to the ends of the span. For simply supported beams, the load on the wall tends to travel to the sections near the supports since they are regions of greater stiffness.

Paes [2] reported that this effect is relevant when the interaction between the masonry wall and its support structure is analyzed. This behavior influences vertical load transfer, resulting in some of the load at the center of the beam traveling to the supports as an arch (Figure 1). Thus, the internal forces of the beam, especially the bending moments, tend to decline, with stress concentration at the extremities of the walls and normal vertical tensile stress in the central part of the deep beam (Figure 1). If these tensile stresses reach the tensile strength of the block-mortar interface, the wall and beam may separate. In the case of single-span beams, this separation generally occurs in the middle of the span, where vertical tensile stress is greater, accentuating the direct transfer of loads to the supports, as reported by Nascimento et al. [4], Barbosa [1] and Medeiros [5].

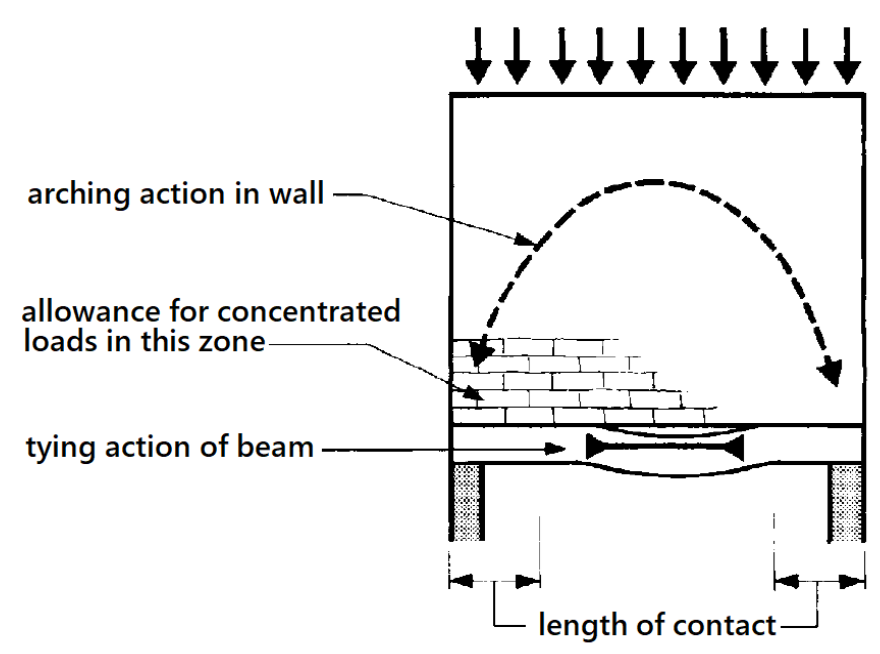

Figure 1. Joint action of the wall-beam system. Adapted: Haseltine, Moore [3].

Silva [6] states that typical structural masonry buildings normally have a ceiling height of $2.80 \mathrm{~m}$, requiring spans of more than $4.0 \mathrm{~m}$ to compensate for the abovementioned behavior. In this case, studies using numerical modeling of only one ceiling height is sufficient to assess the phenomenon and its consequences in terms of beam forces and wall stresses.

\section{COMPUTATIONAL MODELING OF STRUCTURAL MASONRY WALLS}

Numerical simulations are essential to understanding structural behavior and developing efficient formulations that enhance the design. However, to obtain reliable numerical models, a complete description of the materials is required as well as validation by comparing with experimental results. 
Given that the properties of the materials are represented, masonry can be simulated in three ways: micromodeling; simplified micromodeling; and macromodeling. According to Rots [7], Lourenço [8] and Holanda [9], each of these methods requires a set of material characteristics and should be applied for a distinct problem.

In detailed and simplified micromodeling, continuous elements are considered for discontinuous units and elements for the unit/mortar interface. The detailed method considers the stand-alone discretization of the masonry components, taking into account the modulus of elasticity, Poisson's coefficient and optionally, the inelastic properties of both the unit and the mortar, according to Nascimento [10]. The author also states that in simplified modeling each joint is associated with an average interface, while the units are expanded to maintain the geometry. Masonry is considered a group of elastic units adhered to the joints by potential fracture lines and/or slipping, such that all the linearity of the problem is attributed to the joint. Both micromodeling methods can be applied to analyses of computational models with small-scale geometry, where the local behavior must be more accurately verified.

According to Holanda [9], in macromodeling, there is no distinction between block and mortar, with masonry classified as a composite that can be considered isotropic, orthotropic or anisotropic depending on the data available. This global modeling of masonry is suitable for analyzing large structures, where masonry panels are large compared to the units and joint thickness. Thus, macromodeling is the most appropriate method to numerically model wall-beam systems in a building because it addresses the behavior of the structural system. Several authors have proposed models along this same line, such as Nascimento et al. [4], Barbosa [1], Paes [2] and Medeiros [5], a procedure adopted here.

With respect to the elements, several models analyze and design structural walls of reinforced concrete and masonry, strut-and-tie models, truss analogies, use of linear or flat finite elements and equivalent frame models.

According to Testoni [11], the flat finite element model encompasses several behavioral traits of walls in structural analysis. However, to obtain more detailed results, the number of computational modeling unknowns and parameters become considerably refined and numerous, as well as the results obtained, requiring the user to have specific knowledge. As a result, the modeling process and analysis of results may become cumbersome and arduous. Thus, applying sophisticated structural models is no longer a viable alternative for conventional structural designs in structural engineering. This author also reports that equivalent frame models represent walls that use linear elements, and can be analyzed considering frames alone or linked to each other, forming plane frames. Different plane frames can be connected to make a three-dimensional frame. a model used to analyze structural cores and structural masonry buildings.

Nascimento et al. [4] proposed a variation of equivalent frame models to analyze wall-beam interaction. The difference in this modeling is that they use bar elements in both the support beam and the masonry wall, the latter discretized using a grid network with multiple vertical and horizontal bars instead of bars alone and connected only to the floor level. In order to enhance this computational model, Medeiros [5] made a number of changes, such that both investigations conduct an extensive study of the new modeling, comparing it with a model that discretizes walls with shell finite elements, in order to analyze the performance of the computational model proposed. Analyses demonstrated that the equivalent frame model was consistent in analyzing wall-beam interaction for any arrangement of openings, beam spans and support conditions.

It is important to underscore that Medeiros [5] also compared the equivalent frame model with the experimental results obtained by Rosenhaupt [12]. The experimental results were assessed for normal stresses at the bottom of the wall and support beam deflection. The analyses conducted indicated that the normal stress peaks were relatively superior to computational models, which was expected after the linear analysis carried out. However, considering an average normal stress value for two neighboring frames in the equivalent frame model, this difference declines substantially. The maximum beam axial force was significantly near that assessed in the experiment. Thus, excellent correlations were obtained, confirming the capacity of simulating wall-beam interaction using the proposed model.

In her study to perfect the equivalent frame model, Lopes [13] proposed calibrating the thickness and stiffness of grouted frames, in order to obtain easy-to-interpret results. A more suitable analysis of stresses is conducted using the net area of the elements. Nevertheless, the author also assessed a model considering the gross wall area, obtaining results consistent with those of modeling using the net area.

Another relevant aspect for analyses are the possible eccentricities between the walls and support beams. The lateral surface of masonry, primarily on the walls of building facades, is typically aligned with the beam surface, as illustrated in Figure 2, resulting in eccentricity and a twisting moment in the beam, which should be properly assessed. This study was initiated by Lopes [13] using planar models, showing the need for further analyses.

Thus, the need for studies and subsequent improvement of consistent, safe and simple alternative modeling justifies the present investigation, and is relevant for enhancing the equivalent frame model and in-depth analysis of the behavior of the structural masonry system. 


\section{MOLD OF THE REINFORCED CONCRETE TRANSITION STRUCTURE}

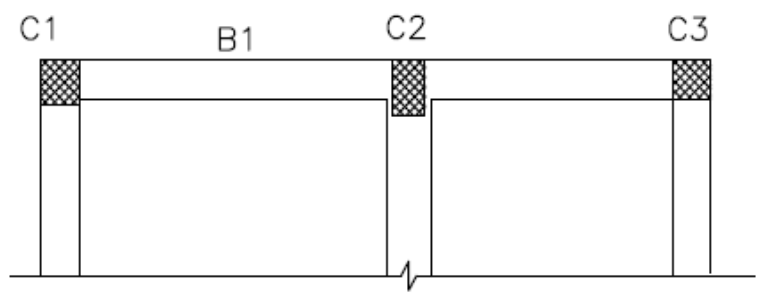

MOLD OF THE FIRST ROW OF STRUCTURAL MASONRY

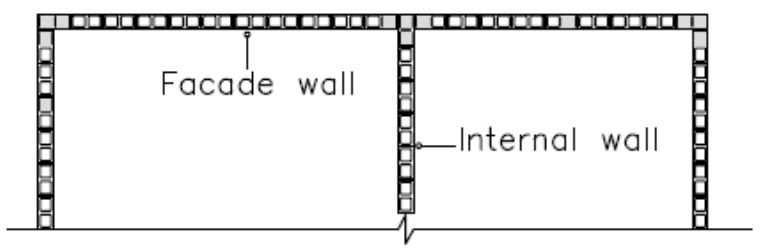

MOLD OF THE SUPPORT STRUCTURE + FIRST ROW

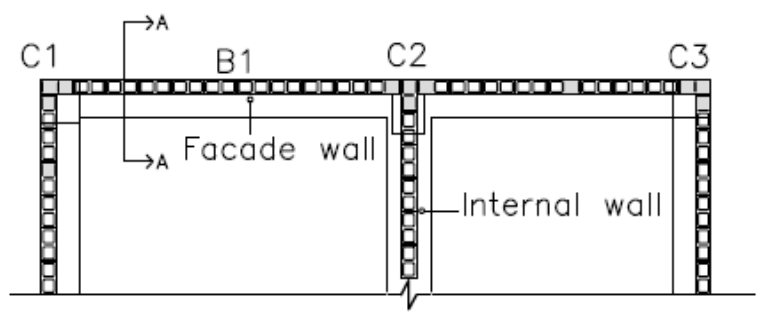

CROSS SECTION A-A
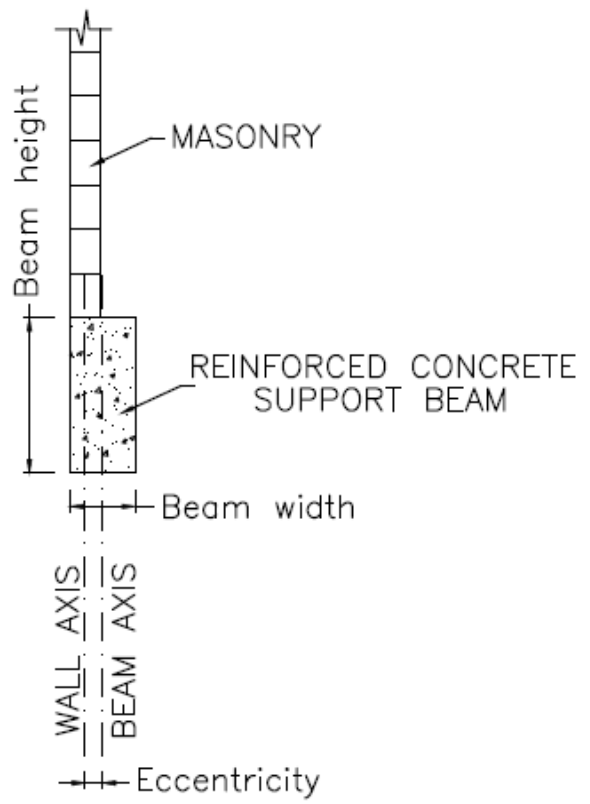

Figure 2. Layout of eccentricity between facade walls and support beam.

\section{MODELS ADOPTED IN ANALYSES}

This study proposes using the equivalent frame model described by Nascimento et al. [4], considering the calibrations developed by Medeiros [5] and Lopes [13], in order to analyze different configurations of the wall-beam system in a real structural masonry building. Analyses were conducted to compare transition structures, simulated by two and three-dimensional models, and reinforced concrete support beams were designed with and without considering the effects of torsion caused by eccentricity between the wall and beam.

The optimal grid proposed by Medeiros [5], who defined it after conducting numerous tests with different grids and support conditions, was used. Discretization consisted of arranging vertical and horizontal bars 15 and $20 \mathrm{~cm}$ apart in order to coincide with the axis of each hole in the blocks and the axis of each course, respecting the layout of the walls. Figure 3 illustrates discretization in the three-dimensional model of walls W30 and W31 with the respective transition structure, from which we can observe the distribution of vertical and horizontal bars to simulate the walls, and the horizontal and vertical bars corresponding to the transition structure, conducted according to the procedure described. The darker bars represent the grouted sections and their lighter counterparts the non-grouted sections.

The linear elastic behavior of the materials was assessed in all analyses and the following support beam forces were evaluated: shear force, axial force, bending moment, twisting moment and vertical displacements. In addition, normal and shear stresses at the bottom of the wall were also analyzed.

In the present study, the same building used by Medeiros [5] was adopted. Vertical loading was applied at the top of the walls, representing a 21-floor structural masonry building using concrete blocks. For transition structure beams, the sections varied according to the floor plans presented in Figure 4 and the isotropic material with longitudinal and transverse moduli of deformation presented in Table 1 was considered. These were determined based on guideline NBR 6118 [14] for concrete with $\mathrm{f}_{\mathrm{ck}}=25 \mathrm{Mpa}$.

In the case of non-grouted masonry, the material was considered orthotropic, attributing half of the value of the vertical direction to the horizontal longitudinal modulus of elasticity. According to NBR 15961-1 [15] and Parsekian et al. [16], compressive strength parallel to the horizontal laying joint in hollow blocks is $50 \%$ lower than 
compression perpendicular to the joint, which generated the ratio between the moduli in both directions, given that these values are obtained as a function of the characteristic strength of prisms. Isotropic material was considered in both the vertical and horizontal sections of grouted masonry. The values adopted for specific gravity and the longitudinal and transverse moduli of elasticity for masonry are shown in Table 1, determined based on NBR 15961-1 [15] for a prism with $\mathrm{f}_{\mathrm{pk}}=12 \mathrm{MPa}$.

Table 1. Physical properties of the materials used in modeling [5].

\begin{tabular}{cccc}
\hline Material & $\begin{array}{c}\text { Specific weight } \mathbf{\Upsilon} \\
\left(\mathbf{k N} / \mathbf{m}^{\mathbf{3}}\right)\end{array}$ & \multicolumn{2}{c}{ Modulus of elasticity (MPa) } \\
\cline { 2 - 4 } & 25 & Longitudinal & Transverse \\
\hline Beam concrete & 22 & 23800 & 9917 \\
\hline Grouted masonry & 14 & 16320 & 8160 \\
\hline Ungrouted masonry & 9600 & 4800 \\
\hline
\end{tabular}

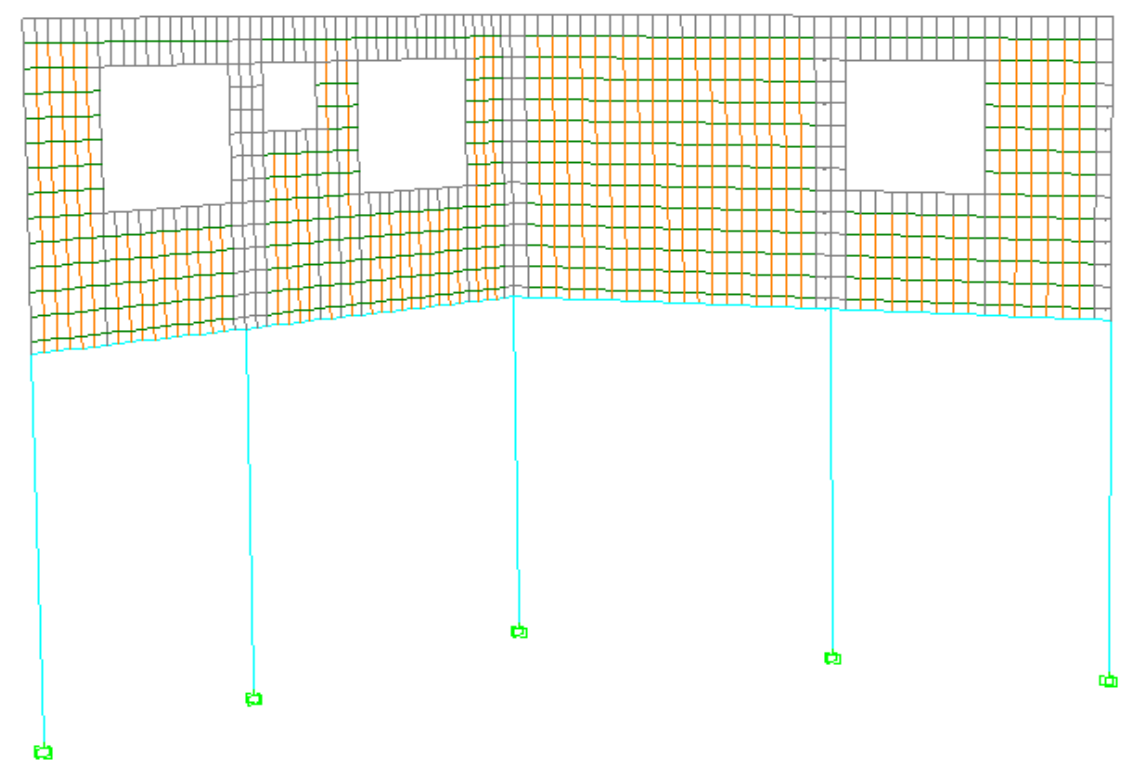

Figure 3. W30 and W1 discretization in the three-dimensional model.

It is important to underscore that the ratio between the characteristic simple compressive strength of a prism and a block $\left(f_{\mathrm{pk}} / \mathrm{f}_{\mathrm{bk}}\right)$ was $60 \%$, resulting in a block with $\mathrm{f}_{\mathrm{bk}}=20 \mathrm{MPa}$, and the ratio between the grouted and hollow prism was 1.7. These efficiency values are considered reasonable and achievable for high-strength blocks, as shown in the experimental study of Fortes [17]. However, before executing the construction project, tests should be conducted to determine prism strength and when the appropriate levels are not achieved, a higher-strength block should be used to guarantee the prism strength stipulated in the design. Further details on this issue can be found in Parsekian et al. [16] and Fortes [17].

In the panels assessed by Medeiros [5], the thickness of the transverse section of the grouted frames was doubled to take into account the larger area of these elements. Simultaneously, the longitudinal modulus of elasticity of grouted elements was attributed to these same frames, which, if not duly assessed, leads to a duplicate effect.

In her study to perfect the equivalent frame model, Lopes [13] proposed calibrating thickness and stiffness of grouted frames, in order to obtain easy-to-interpret results. After the variations were assessed, a more adequate analysis of stresses was carried out using the net area of the elements, and Model 3, presented in Table 2, was considered the most suitable for analysis. Nevertheless, the author also assessed a model considering the gross wall area, obtaining results consistent with those of modeling using the net area. Thus, all the analyses in this study considered the characteristics of Model 2 presented in Table 2. 


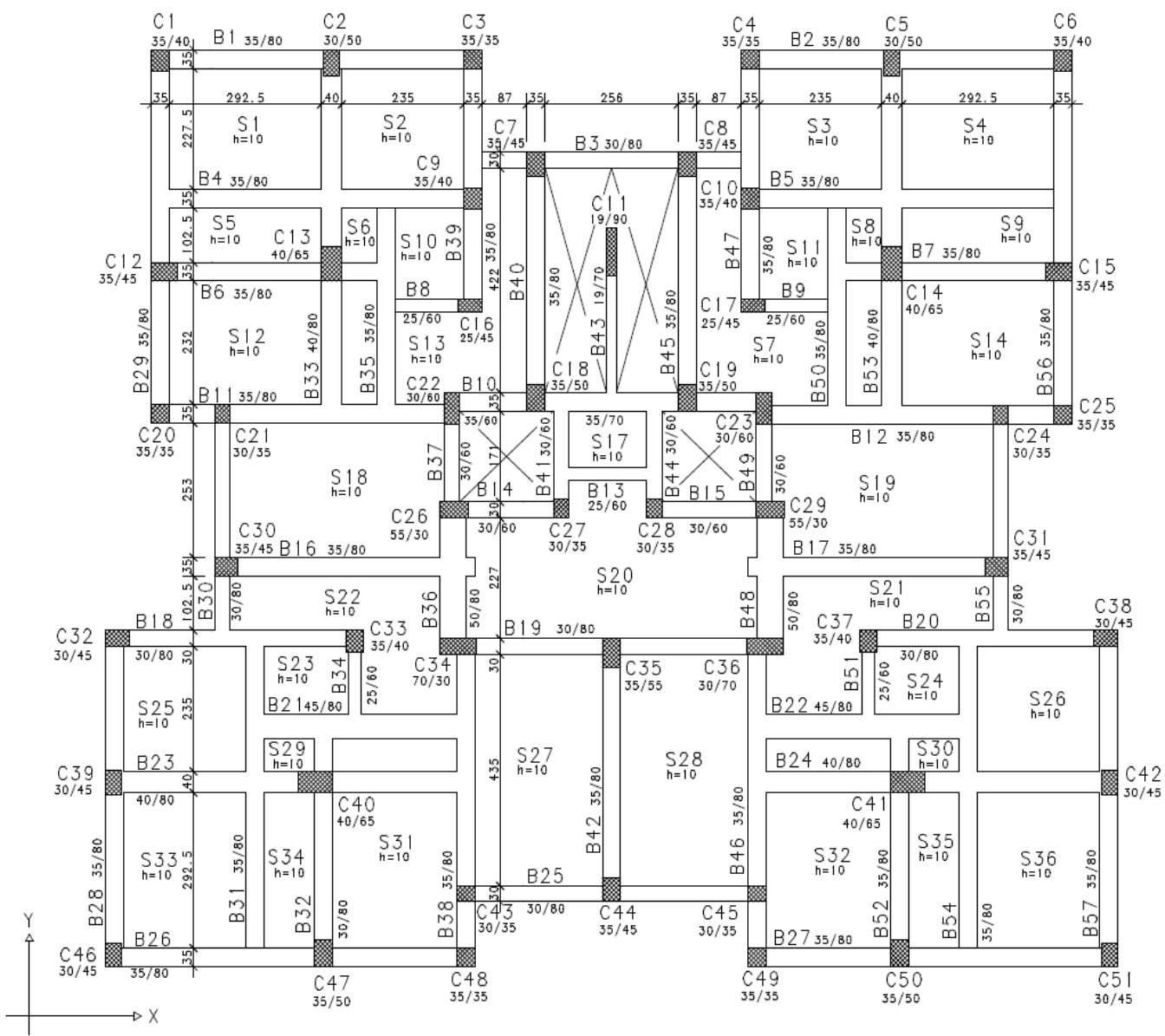

Figure 4. Formwork plan of the support concrete structure. Adapted: Medeiros [5].

Table 2. Variations adopted for the model [13].

\begin{tabular}{cccccc}
\hline \multirow{2}{*}{ Models } & \multicolumn{3}{c}{ Modulus of elasticity (MPa) } & & \multirow{2}{*}{ Element thickness (cm) } \\
\cline { 2 - 5 } & \multirow{2}{*}{ Grouted Masonry } & \multicolumn{2}{c}{ Ungrouted masonry } & & Grouted \\
\cline { 2 - 5 } & & Longitudinal & Transverse & 28 & Ungrouted \\
\hline Reference & 16320 & 9600 & 4800 & $1.7 \times 14$ & 14 \\
\hline 1 & 9600 & 9600 & 4800 & 14 & 14 \\
\hline 3 & 16320 & 9600 & 4800 & 14 & 7 \\
\hline
\end{tabular}

Analyses were conducted for four walls of the building, whose selection criteria were the following:

- Walls 1 and 30 were selected for exhibiting several openings in their geometry and interconnections between them at one of the ends; in addition, the transition structure beams that support them are continuous, with beam B1 for wall 1 and B29 for wall 30;

- Walls 41 and 3 were selected for the interconnection between them and primarily because the former is an important vertical shear panel in the building; beam V3, which supports wall 3, is continuous, while beam B40, which supports wall 41 , has only one span.

The models that generated the results were denominated as follows:

- 2D model - Planar model with total permanent and accidental load action, without considering equivalent wind loads;

- 3D model - Three-dimensional model with total permanent and accidental load action, without considering equivalent wind loads;

- 3DV model - Three-dimensional model with total permanent, accidental and equivalent wind load action, through combinations of actions. 
It is important to underscore that wind action was incorporated into the models by applying equivalent vertical loads to the top of the walls, in order to create the corresponding binaries according to the direction of the wind. Moreover, the effect of slabs (rigid diaphragms) was incorporated into modeling in order to guarantee that restraint straps were securely fit to the top of the structural walls.

The twisting moment, corresponding to the eccentricity between the vertical plane of the wall and the longitudinal axis of the beam, was applied to the model after previous processing to determine the vertical forces at the bottom of the walls. Once the vertical forces were determined, the intensity of the twisting moment to apply was obtained by multiplying the eccentricity of the corresponding vertical frame, and the resulting values were applied directly to the horizontal frames corresponding to the support beams of the structural walls.

Figure 5 illustrates the structural wall plan of the building, while the geometric characteristics of the walls under study (walls 1, 30, 41 and 3) are depicted in Figure 6. For further clarification, the results of 3DV Models for walls 1 and 30 correspond to wind action in direction $\mathrm{X}$ on the plan, while walls 3 and 41 correspond to wind action in direction $\mathrm{Y}$ on the plan.

\section{RESULTS AND DISCUSSION}

\subsection{Comparison between planar and three-dimensional modeling}

\subsubsection{Wall 1}

Figure 7a illustrates normal stresses at the bottom of the wall, showing similar behavior for the three models analyzed. Despite the proximity between curves, the three-dimensional models exhibited more pronounced peak stress than that of the planar model. Medeiros [5] reported that this increase in peak stress may be due to the effect of the intersection between the walls, not considered in the planar model, given that in three-dimensional modeling, a single frame represents the intersection between walls, receiving load from all those that converge on the intersection. In addition, Figure 7a shows that the intensity of the stresses around the peaks are also greater, notably in the sections on columns $\mathrm{C} 2$ and $\mathrm{C} 3$, which may also be attributed to the three-dimensional effect of the assembly. It is important to underscore that stress distribution associated with the $3 \mathrm{DW}$ Model, illustrated in the following figures, represent the envelope, considering the reversed wind direction, which explains the tendency for increases to always occur in three-dimensional models.

In the case of shear stress distribution at the bottom of the wall (Figure 7b), the planar model exhibited slightly higher peak intensities at the ends of the panel compared to three-dimensional models, in the center. In the intermediate sections, far from the regions on columns, the stresses obtained with the 2D and 3D models exhibited similar intensities, and those obtained with the 3DW model were slightly lower.

These results are illustrated in Table 3, showing considerable increases in peak stress with the three-dimensional model, notably in the regions of columns $\mathrm{C} 2$ and $\mathrm{C} 3$, with differences of up to $112 \%$ in relation to the planar model when considering wind action. These results indicate the real need for three-dimensional modeling and underscore the influence that the wind can exert on the distribution of normal stresses at the bottom of the wall. This suggests, for example, the possible need for grouting reinforcement in the corresponding region and/or a prism with greater compressive strength.

With respect to shear stress peak intensities, the three-dimensional models displayed lower values than those of their planar counterpart, in contrast to what occurred with normal stresses.

In relation to the support beam, Figure 8 shows the distribution of axial force, shear force, bending moment and displacements along its length, demonstrating similar behavior between the 3 models assessed. Table 4 contains the most significant graph values and the percentage differences. Figure 8a shows the differences obtained for maximum axial force intensity with the 3DW model, where the increasing trend was maintained on practically the entire length of the support beam. This behavior in the 3DW model may be associated with higher shear stress along the bottom of the wall, since this stress corresponds to the axial load acting on the beam. Likewise, shear stress at approximately the $1.8 \mathrm{~m}$ coordinate exhibits null intensity and maximum axial force. This could be due to the same shear stress signals (acting in the same direction) up to this coordinate, after which the signal changes (opposite direction), resulting in a decline in axial force in the section. 


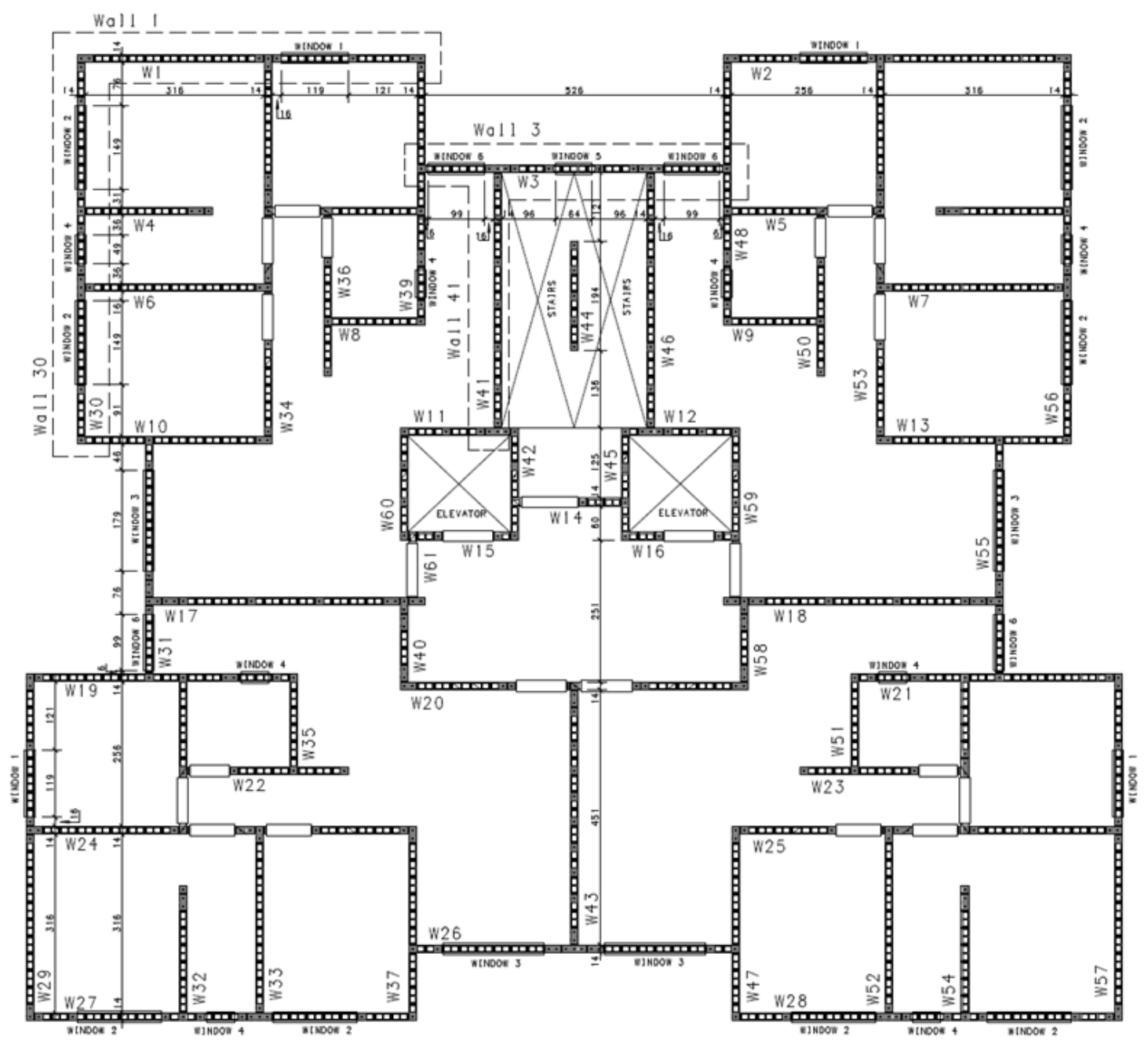

Figure 5. Wall layout, highlighting the walls under study. Adapted: Medeiros [5].

Table 3. Normal and shear stresses at the bottom of Wall 1.

\begin{tabular}{|c|c|c|c|c|c|c|c|c|c|}
\hline \multirow{2}{*}{ Model } & \multicolumn{9}{|c|}{ Normal stress (MPa) - Maximum values } \\
\hline & Region C1 & $\Delta$ 2D & $\Delta 3 \mathrm{D}$ & Region C2 & $\Delta 2 \mathrm{D}$ & $\Delta$ 3D & Region C2 & $\Delta 2 \mathrm{D}$ & $\Delta 3 \mathrm{D}$ \\
\hline $2 \mathrm{D}$ & 7.03 & - & - & 3.28 & - & - & 3.36 & - & - \\
\hline $3 \mathrm{D}$ & 8.77 & $25 \%$ & - & 5.18 & $58 \%$ & - & 5.33 & $59 \%$ & - \\
\hline 3DW & 10.52 & $50 \%$ & $20 \%$ & 6.17 & $88 \%$ & $19 \%$ & 7.13 & $112 \%$ & $34 \%$ \\
\hline \multirow{2}{*}{ Model } & \multicolumn{9}{|c|}{ Shear stress (MPa) - Maximum values } \\
\hline & Region C1 & $\Delta_{2 D}$ & $\Delta 3 \mathrm{D}$ & Region C2 & $\Delta_{2 \mathrm{D}}$ & $\Delta_{3 D}$ & Region C2 & $\Delta_{2 D}$ & $\Delta 3 \mathbf{D}$ \\
\hline $2 \mathrm{D}$ & 0.60 & - & - & 0.40 & - & - & 0.16 & - & - \\
\hline $3 \mathrm{D}$ & 0.47 & $-22 \%$ & - & 0.40 & $0 \%$ & - & 0.11 & $-31 \%$ & - \\
\hline 3DW & 0.51 & $-15 \%$ & $9 \%$ & 0.40 & $0 \%$ & $0 \%$ & 0.17 & $6 \%$ & $55 \%$ \\
\hline
\end{tabular}

With respect to shear force, Figure $8 \mathrm{~b}$ shows significant differences in intensities only in the supports, resulting in an $18 \%$ rise from changing the type of model and $11 \%$ when including wind action in analyses. Once again, this result can be explained by the three-dimensional effect of the assembly, where part of the load acting on a wall migrates to the intersecting wall.

With respect to bending moments, three-dimensional models are also associated with greater intensities when compared to the planar model, resulting in a $6 \%$ higher negative bending moment with three-dimensional modeling, and $17 \%$ higher than when the effect of wind is considered. In the case of positive bending moments, an increase (38\%) 
occurred only in the section between columns $\mathrm{C} 2$ and $\mathrm{C} 3$, corresponding to the result of the 3DW model. This behavior is due to the distribution of normal stress at the bottom of the wall, where the action of higher-intensity stress was observed on the beam spans of the $3 \mathrm{DW}$ model.

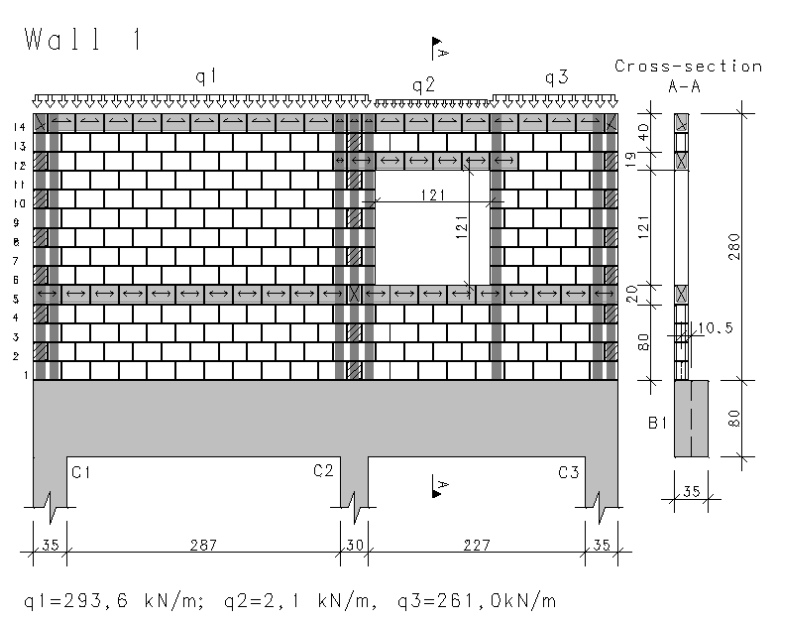

(a)

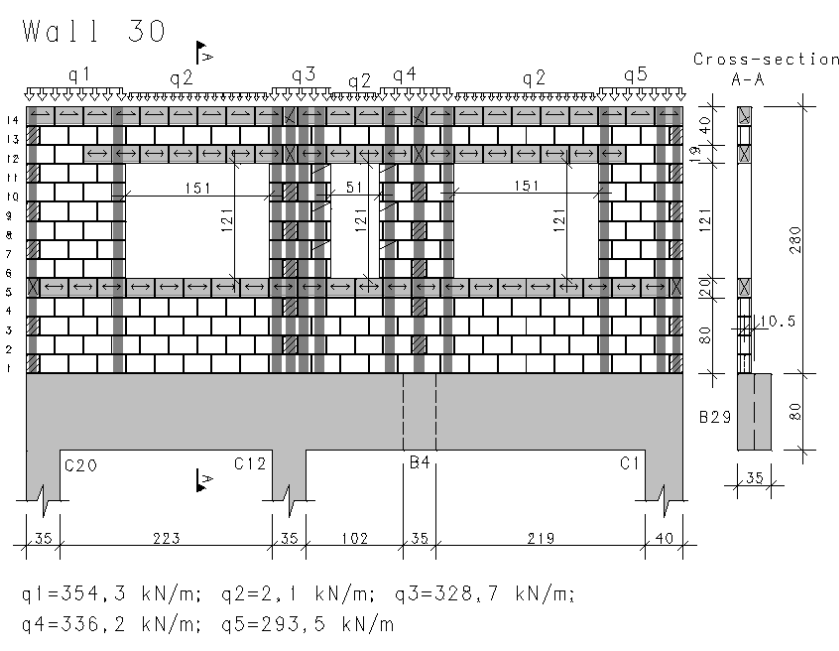

(b)

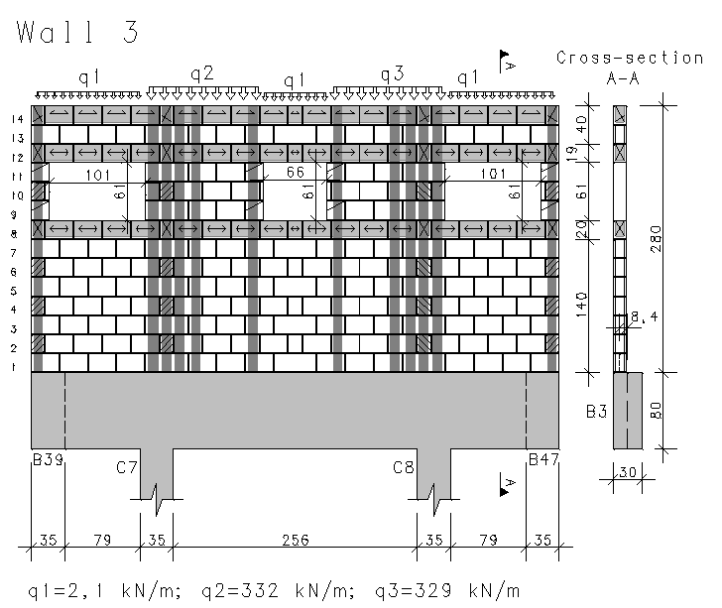

(c)

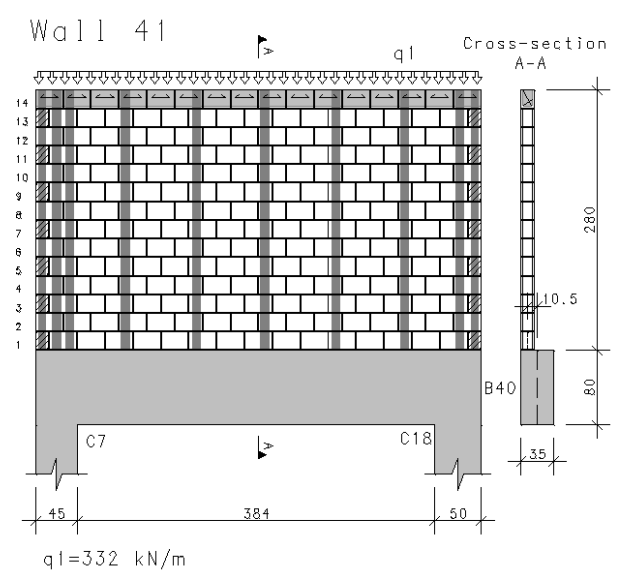

(d)

Figure 6. Walls details. (a) Wall 1; (b) Wall 30; (c) Wall 3; (d) Wall 41.

Table 4. Maximum forces and displacements in the support beam of Wall 1.

\begin{tabular}{|c|c|c|c|c|c|c|c|c|c|c|c|c|}
\hline \multirow[t]{2}{*}{ Model } & \multicolumn{3}{|c|}{$\begin{array}{c}\text { Axial force } \\
(\mathbf{k N})\end{array}$} & \multicolumn{3}{|c|}{$\begin{array}{c}\text { Shear force } \\
(\mathbf{k N})\end{array}$} & \multicolumn{3}{|c|}{ Bending moment $(\mathbf{k N} \cdot \mathbf{m})$} & \multicolumn{3}{|c|}{ Displacements (cm) } \\
\hline & Maximum & $\Delta_{2 \mathrm{D}}$ & $\overline{\Delta_{3 D}}$ & Maximum & $\Delta_{2 D}$ & $\overline{\Delta_{3 D}}$ & Maximum & $\Delta_{2 \mathrm{D}}$ & $\overline{\Delta_{3 D}}$ & Maximum & $\Delta_{2 D}$ & $\overline{\Delta_{3 D}}$ \\
\hline $2 \mathrm{D}$ & 57.83 & - & - & 396.68 & - & - & 183.50 & - & - & 0.11 & - & - \\
\hline $3 \mathrm{D}$ & 65.89 & $14 \%$ & - & 467.57 & $18 \%$ & - & 194.70 & $6 \%$ & - & 0.16 & $45 \%$ & - \\
\hline 3DW & 85.69 & $48 \%$ & $30 \%$ & 519.26 & $31 \%$ & $11 \%$ & 228.09 & $24 \%$ & $17 \%$ & 0.17 & $55 \%$ & $6 \%$ \\
\hline
\end{tabular}


Wall lenght (m)

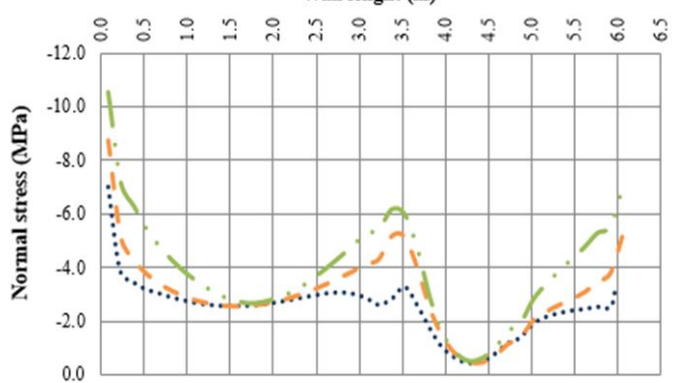

(a)

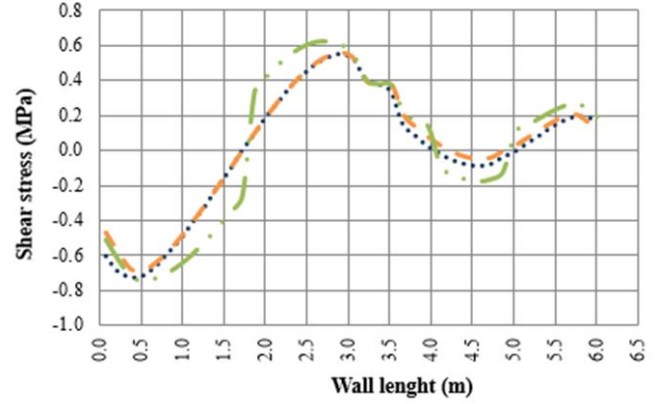

(b)

$\cdots$ 2D Model - -3D Model — 3DW Model

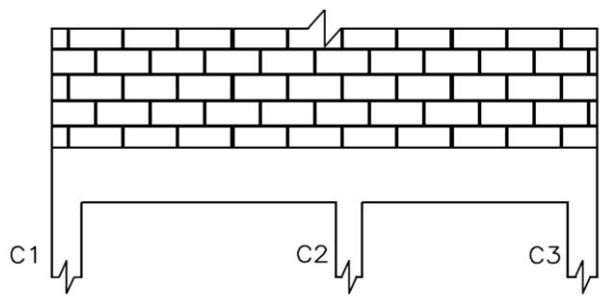

Figure 7. Stress distribution at the bottom of Wall 1: (a) Normal stress; (b) Shear stress

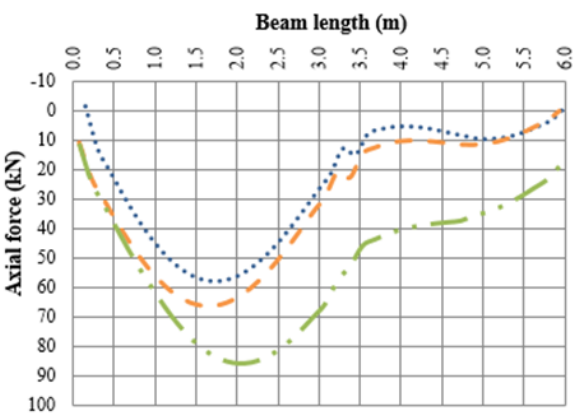

(a)

Beam length(m)

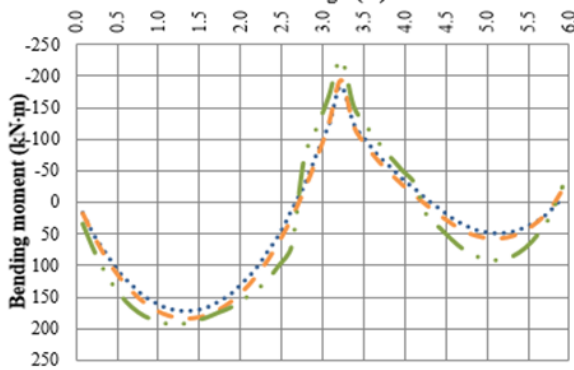

(c)

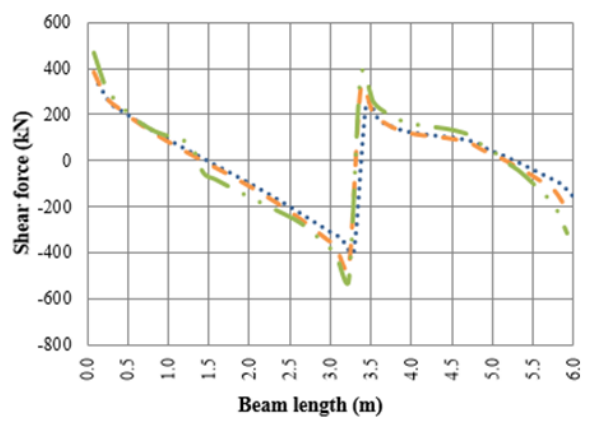

(b)

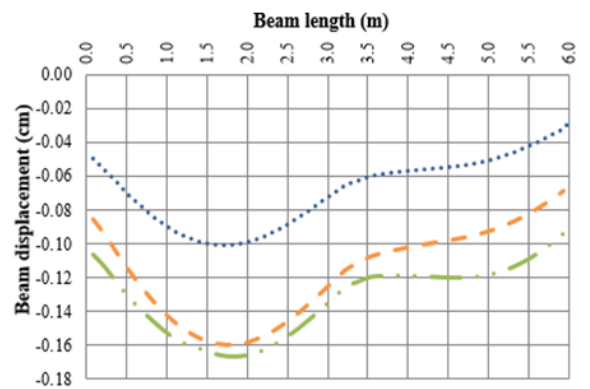

(d)

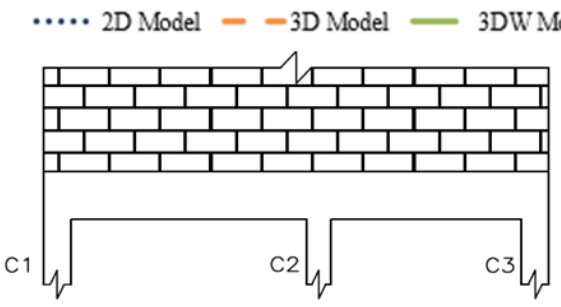

Figure 8. Forces on the support beam of wall 1: (a) Axial force; (b) Shear force; (c) Bending moment; (d) Vertical displacement. 
In regard to beam displacement shown in Figure 8d, the significant difference between 3D and 3DW models and the 2D model, may be due to axial deformation in the support columns submitted to greater vertical load in these models. With respect to the results obtained, the absolute values are considered small in relation to the beam spans, and well below the service limits established in Brazilian guideline NBR 6118 [14].

Despite the importance of wall 1 for bracing the building, compared to the 3D model, the 3DW model exhibited stresses at the bottom of the wall, with significant differences only in the peaks and small increases in the support beam, except for axial force. This behavioral trend is due to the fact that wind distributes variable stresses along the length of the wall. Maximum stresses occur at the extremities, where vertical load stresses are concentrated. However, it is important to emphasize that despite being small, these increases may significantly change beam design since it is a support beam subjected to bending and traction.

\subsubsection{Wall 30}

Figure $6 \mathrm{~b}$ illustrates the geometry of wall 30 , arranged perpendicularly to wall 1 at its left end in the equivalent frame model. Figure 9 shows the distribution of normal and shear stresses at the bottom of the wall, exhibiting similarity in the curves for the results of the three models assessed, except the peak at the $2.75 \mathrm{~m}$ coordinate. This effect, observed only in the three-dimensional models, refers to the end of the transverse wall interconnected with Wall 30 in this section, as depicted in Figure 5. Despite the similar overall aspect in the 3D and 3DW models, significantly higher intensities occurred, resulting in differences in the region of column $\mathrm{C}$, of 47 and $76 \%$, respectively, in relation to the $2 \mathrm{D}$ model. Considering wind action in the analyses caused an $20 \%$ increase in maximum normal stress in this region (Table 5) indicating the importance of considering it in the analyses. Moreover, due to the redistribution of stresses emanating from the interconnecting walls, three-dimensional models always exhibit higher intensities than those of the planar model.

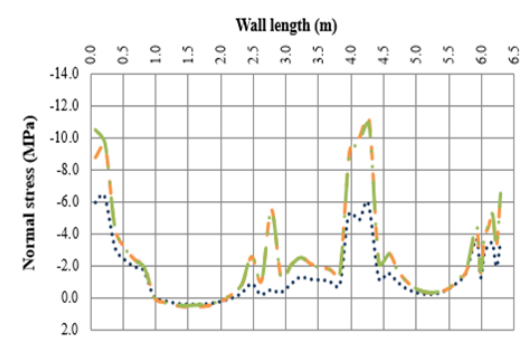

(a)

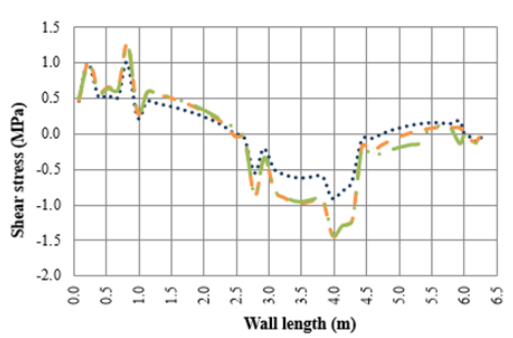

(b)

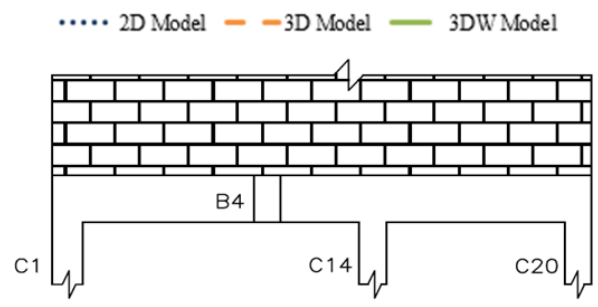

Figure 9. Stress distribution at the bottom of Wall 30: (a) Normal stress; (b) Shear stress.

Table 5. Normal and shear stresses at the bottom of Wall 30.

\begin{tabular}{|c|c|c|c|c|c|c|c|c|c|}
\hline \multirow{2}{*}{ Modelo } & \multicolumn{9}{|c|}{ Normal stress (MPa) - Maximum values } \\
\hline & Region C1 & $\Delta_{2 D}$ & $\Delta 3 \mathbf{D}$ & Região C14 & $\Delta_{2 D}$ & $\Delta 3 \mathbf{D}$ & Região C20 & $\Delta_{2 D}$ & $\Delta 3 D$ \\
\hline $2 \mathrm{D}$ & 5.97 & - & - & 5.91 & - & - & 3.56 & - & - \\
\hline $3 \mathrm{D}$ & 8.77 & $47 \%$ & - & 11.14 & $88 \%$ & - & 6.64 & $87 \%$ & - \\
\hline 3DW & 10.52 & $76 \%$ & $20 \%$ & 10.82 & $83 \%$ & $-3 \%$ & 6.54 & $84 \%$ & $-2 \%$ \\
\hline \multirow{2}{*}{ Modelo } & \multicolumn{9}{|c|}{ Shear stress (MPa) - Maximum values } \\
\hline & Region C1 & $\Delta_{2 D}$ & $\Delta_{3 D}$ & Região C14 & $\Delta_{2 D}$ & $\Delta_{3 \mathbf{D}}$ & Região C20 & $\Delta_{2 D}$ & $\Delta_{3 D}$ \\
\hline $2 \mathrm{D}$ & 0.46 & - & - & 0.91 & - & - & 0.07 & - & - \\
\hline $3 \mathrm{D}$ & 0.44 & $-4 \%$ & - & 1.43 & $57 \%$ & - & 0.06 & $-14 \%$ & - \\
\hline 3DW & 0.42 & $-9 \%$ & $-5 \%$ & 1.42 & $56 \%$ & $-1 \%$ & 0.08 & $14 \%$ & $33 \%$ \\
\hline
\end{tabular}


Column C1, a common support for support beams B1 and B29 of walls 1 and 30, respectively, shows coincident maximum normal stress values at the bottom of these walls of $8.77 \mathrm{MPa}$, obtained using the 3D model, as depicted in Tables 3 and 5. In the case of the 2D model, maximum stress on the frame on top of column $\mathrm{C} 1$ is $7.03 \mathrm{MPa}$ in wall 1 and $5.97 \mathrm{MPa}$ in wall 30. Since modeling considered linear elastic behavior, overlapping effects were assessed, resulting in an intensity of $13.0 \mathrm{MPa}$, corresponding to a difference of $48 \%$ in relation to the 3D model. The 3D model obtained a lower intensity because analysis was conducted on a single vertical frame that interacts with two walls in this model, and only one in the 2D model, causing stress distribution along a smaller region. This indicates that using planar modeling could result in overestimating maximum normal stresses, demonstrating the need to use three-dimensional modeling in the analyses.

In relation to shear stresses at the bottom of the wall, Figure $9 \mathrm{~b}$ illustrates their distribution and Table 5 the highest values. The same behavioral trend was observed in the three models evaluated, with more intense peaks in the 3D models, and significant differences associated only with the section of column C14, slightly different from what occurred for normal stresses. This difference in increasing trend is related to the several openings in the wall, especially that located between columns P14 and P20, where one of the sides is coincident with the end of the beam span. This hinders the formation of a stressed arch in this span, significantly changing the behavioral trend expected for stress distribution. Beam continuity and the section of masonry below the smallest opening near column $\mathrm{C} 14$ should also be considered, as shown in Figure 6b.

With respect to the support beam, Figure 10a presents the axial force diagram, where higher intensities in the three-dimensional models can be observed, with maximum values of $69.97 \mathrm{kN}, 98.80 \mathrm{kN}$ and $98.67 \mathrm{kN}$, for the 2D, 3D and 3DW models, respectively, and corresponding to differences of $41 \%$ in relation to the 2D model, as illustrated in Table 6. All the models exhibited tensile forces in the section between columns $\mathrm{C} 1$ and $\mathrm{C} 14$. For the section between $\mathrm{C} 14$ and C20, compressive forces occurred along the entire length only with the 3D and 3DW models, while in the 2D model, in the section after coordinate $5.75 \mathrm{~m}$, practically no acting force was observed. This result corroborates the trend of the opening on the side of column C14, eliminating the formation of a stressed arch in the section between P14 and P20, as well as the trend of beam continuity and sections of masonry below the window openings changing shear stress distribution.

Table 6. Maximum forces and displacements in the support beam of Wall 30.

\begin{tabular}{|c|c|c|c|c|c|c|c|c|c|c|c|c|}
\hline \multirow{2}{*}{ Model } & \multicolumn{3}{|c|}{ Axial force $(k N)$} & \multicolumn{3}{|c|}{ Shear force $(k N)$} & \multicolumn{3}{|c|}{ Bending moment $(\mathbf{k N} \cdot \mathbf{m})$} & \multicolumn{3}{|c|}{ Displacements (cm) } \\
\hline & Maximum & $\Delta_{2 \mathrm{D}}$ & $\overline{\Delta_{3 D}}$ & Maximum & $\Delta_{2 D}$ & $\overline{\Delta_{3 D}}$ & Maximum & $\Delta_{2 \mathrm{D}}$ & $\overline{\Delta_{3 D}}$ & Maximum & $\Delta_{2 \mathrm{D}}$ & $\Delta_{3 D}$ \\
\hline $2 \mathrm{D}$ & 69.97 & - & - & 380.73 & - & - & 182.94 & - & - & 0.12 & - & - \\
\hline $3 \mathrm{D}$ & 98.80 & $41 \%$ & - & 577.77 & $52 \%$ & - & 255.12 & $39 \%$ & - & 0.21 & $72 \%$ & - \\
\hline 3DW & 98.67 & $41 \%$ & $0 \%$ & 571.62 & $50 \%$ & $-1 \%$ & 252.70 & $38 \%$ & $-1 \%$ & 0.20 & $71 \%$ & $-1 \%$ \\
\hline
\end{tabular}

With respect to shear forces and bending moments, the trend to consider wind action did not change these forces and the 3D models displayed higher intensities in relation to the planar model, with significant differences in maximum values, as shown in Table 6. These results may be due to the action of higher normal stresses at the bottom of the walls in the three-dimensional models.

Finally, Figure 10d shows that the vertical displacements of the support beam were significantly higher in the three-dimensional models, with differences of around $72 \%$ in relation to the planar model. A large part of this difference can be attributed to greater axial deformation of the columns in 3D models, due to the loading acting on the transverse walls that intersect with Wall 30. In addition, the higher shear forces and bending moments indicate greater loading on the beams of three-dimensional models, which also contributes to increasing vertical displacements. Nevertheless, small values were obtained, far below the guidelines established for service limit states.

Figure 4 shows that beam B4, which is supported by beam B29, is located between columns C1 and C14, on top of wall 30. The effect of this interaction between beams is considered in three-dimensional models, but not the planar model. However, the corresponding load on the beam was manually introduced into the 2D model and all the results presented until then refer to this condition. To illustrate the effect of not including this loading, Figure 11 shows the force diagrams of beam B29, where the total inconsistency in the trend of the results obtained with the 2D model can be observed in the section between P1 and P14, especially shear forces and bending moments. 


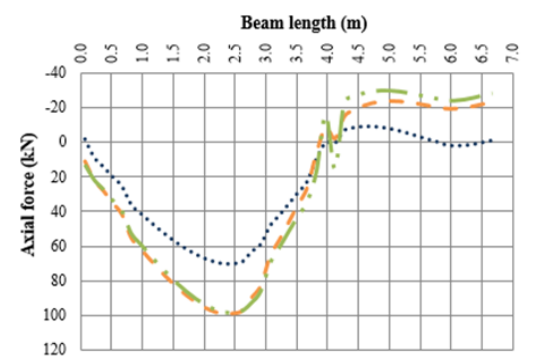

(a)

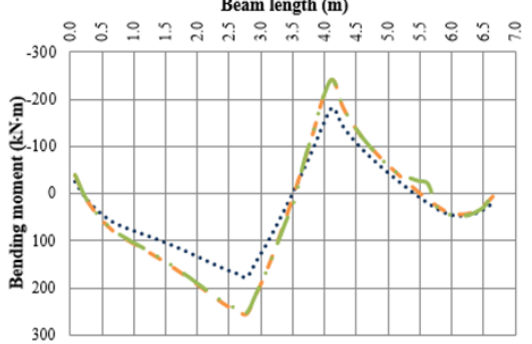

(c)

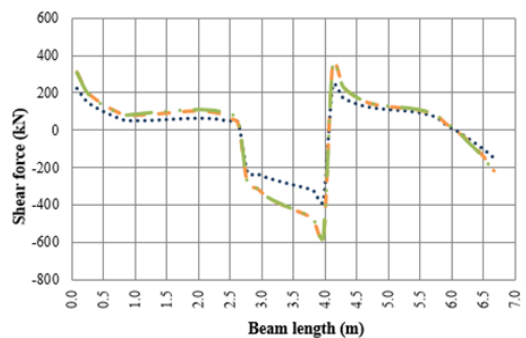

(b)

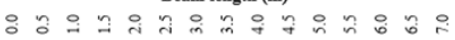

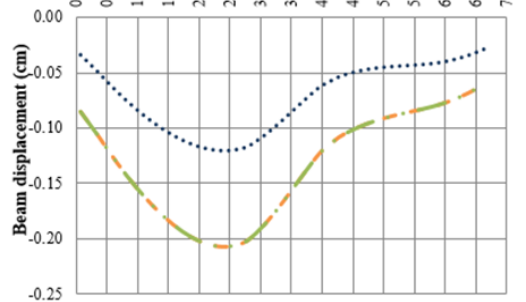

(d)

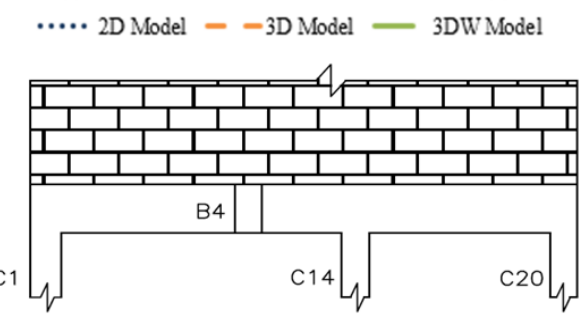

Figure 10. Forces on the support beam of Wall 30: (a) Axial force; (b) Shear force; (c) Bending moment; (d) Vertical displacement.

Beam length (m)

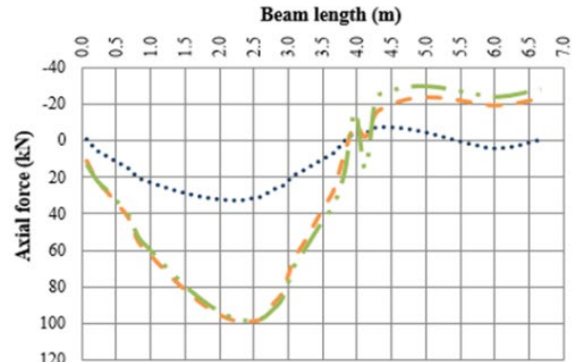

(a)

Beam length $(\mathrm{m})$

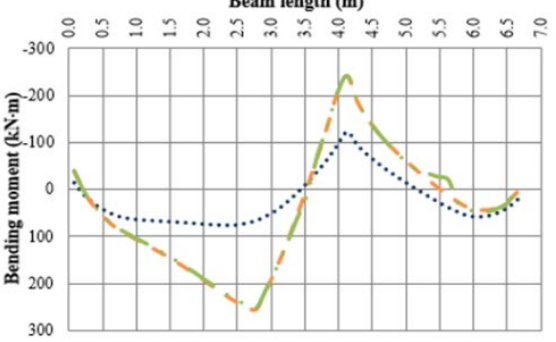

(c)

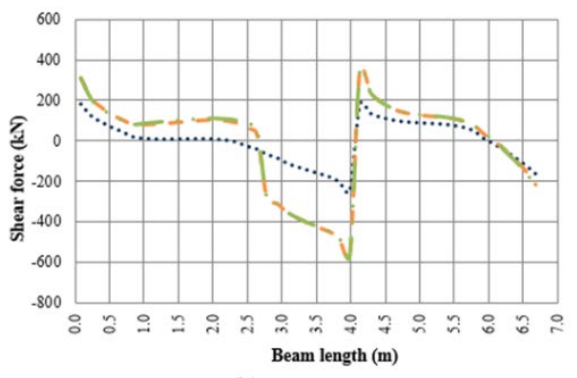

(b)

Beam length (m)

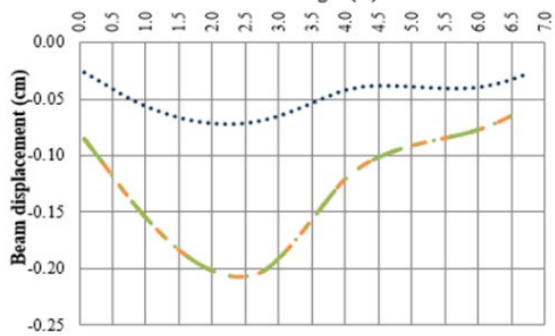

(d)

… 2D Model - -3D Model — 3DW Model

Figure 11. Forces on the support beam of Wall 30 disregarding the load of Beam B4 in the 2D model: (a) Axial force; (b) Shear force; (c) Bending moment; and (d) Vertical displacement. 


\subsubsection{Wall 3}

Figures $6 \mathrm{c}$ and 5 illustrate the geometry of wall 3, demonstrating its interconnection with walls 41 and 46 . In the case of the 2D model, due to the proximity of columns C10 and C11 (Figure 4), the intersections of beam B3 with beams B39 and B47 were considered simple supports. This condition was defined after the vertical displacements obtained with the 3D model were assessed.

Figure 12a shows the normal stresses at the bottom of the wall, where, despite the same curve behavior, the 3D models exhibited significantly higher stresses along the entire length of the wall, with peaks occurring in the column C7 region multiplied by 2.4, which increased by $11 \%$ when wind action was taken into account, as depicted in Table 7 . This aspect can be explained by the interconnection with walls 41 and 46 , which reveals higher vertical loading, redistributed in the corresponding section of wall 3 and only incorporated into in three-dimensional models.

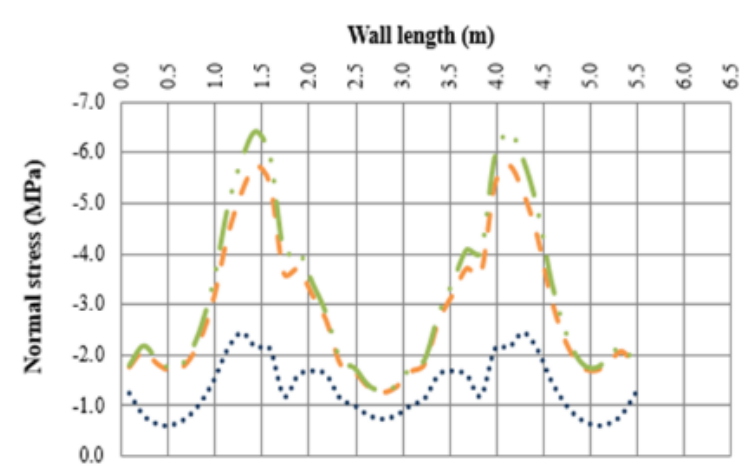

(a)

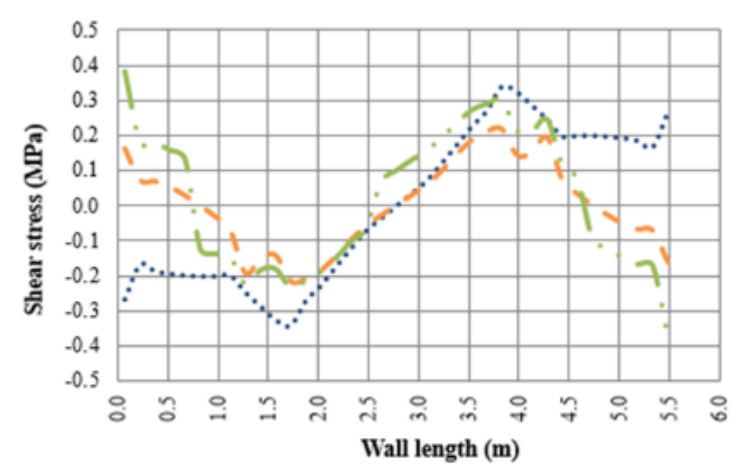

(b)

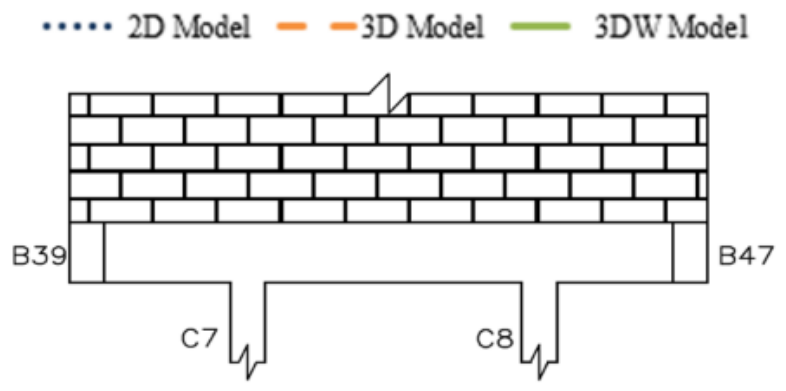

Figure 12. Stress distribution at the bottom of Wall 3: (a) Normal stress; (b) Shear stress.

Table 7. Normal and shear stress at the bottom of Wall 3.

\begin{tabular}{|c|c|c|c|c|c|c|}
\hline \multirow{2}{*}{ Modelo } & \multicolumn{6}{|c|}{ Normal stress (MPa) - Maximum values } \\
\hline & Region C7 & $\Delta 2 \mathrm{D}$ & $\Delta 3 \mathrm{D}$ & Region C8 & $\Delta \mathbf{2 D}$ & $\Delta 3 \mathrm{D}$ \\
\hline 2D & 2.43 & - & - & 2.43 & - & - \\
\hline $3 \mathrm{D}$ & 5.75 & $137 \%$ & - & 5.75 & $137 \%$ & - \\
\hline 3DW & 6.40 & $163 \%$ & $11 \%$ & 6.40 & $163 \%$ & $11 \%$ \\
\hline \multirow{2}{*}{ Modelo } & \multicolumn{6}{|c|}{ Shear stress (MPa) - Maximum values } \\
\hline & Region C7 & $\Delta_{2 D}$ & $\Delta_{3 D}$ & Region C8 & $\Delta_{2 \mathrm{D}}$ & $\Delta_{3 D}$ \\
\hline $2 \mathrm{D}$ & 0.29 & - & - & 0.29 & - & - \\
\hline $3 \mathrm{D}$ & 0.19 & $-34 \%$ & - & 0.19 & $-34 \%$ & - \\
\hline 3DW & 0.22 & $-24 \%$ & $16 \%$ & 0.22 & $-24 \%$ & $16 \%$ \\
\hline
\end{tabular}

With respect to shear stress distribution at the bottom of the wall, as illustrated in Figure 12b, in relation to the 2D, 3D exhibited reverse direction stresses in the end sections of the beam and always lower intensities in the central region. Unlike what occurred with normal stresses, the differences obtained in the region of column $\mathrm{C} 7$ resulted in decreases with far smaller variations (Table 7). With respect to the curves, it is important to underscore that the sections with constant intensities observed in the 2D model correspond to those below the window openings of wall 3, which was not characterized in the 3D and 3DW models. In addition, the maximum absolutes in the three-dimensional models did not occur on the supports of columns 
C7 and C8, but on the supports at the ends, corresponding to beams B39 and B47. All of these changes in shear stress distribution reinforce the need for three-dimensional modeling in order to properly account for the effects of wall-beam interaction.

Considering the $2.75 \mathrm{~m}$ coordinate on the beam and the section to the left, a change in the direction of shear stresses can be observed in the 3D and 3DW models, evidenced by the change in signal, which did not occur in the 2D model. In this case, the vectors associated with the 2D model are arranged from right to left, while in the 3D and 3DW models the same direction can be observed from the $2.75 \mathrm{~m}$ to the $0.75 \mathrm{~m}$ coordinate, delimiting a $2.0 \mathrm{~m}$ section, and reversing direction between the $0.75 \mathrm{~m}$ and $0.0 \mathrm{~m}$ coordinates. This will affect axial force distribution in the beam due to its direct relation with shear stresses at the bottom of the wall.

Figure 13a presents the axial force distribution in the support beam, showing the exclusive occurrence of compressive forces along the entire beam, with higher intensities in the 3D model, while according to the results of the 2D model, the beam is submitted solely to tensile forces. This discrepant result is due to the change in direction of shear stresses at the bottom of the wall, as described before. Taking the middle section between pillars P7 and P8 as reference, and the part of the beam to the left of this section, the integration of shear stresses distributed to the left of the sections defined in this part leads to the axial force value in the section. In addition, when the vectors are arranged from left to right and right to left, compressive and tensile forces, respectively, are induced. Thus, the integration of these stresses only generates tensile forces on the beam of the 2D model. In the 3D and 3DW models, compressive forces are induced from the left end to approximately the $0.75 \mathrm{~m}$ coordinate, and thereafter tensile forces up to the $1.75 \mathrm{~m}$ coordinate, which reduces the initially induced compression. Thus, as illustrated in Figure 13a, the relief in compressive forces was insufficient to induce tensile forces in the sections of the beam in the 3D and 3DW models. This causes radical changes in beam design, where bending-traction forces become bending-compression forces, which, in turn, significantly changes the amount of reinforcement needed to obtain balanced sections in the service limit state. Finally, as occurred in the previously assessed walls, the $2.75 \mathrm{~m}$ coordinate at which the axial force reaches its minimum intensity in the three-dimensional models and maximum in the planar model, corresponds to the coordinate at which shear stresses are annulled at the bottom of the wall. The maximum compressive intensities in the three-dimensional models also correspond to sections with null shear stresses.

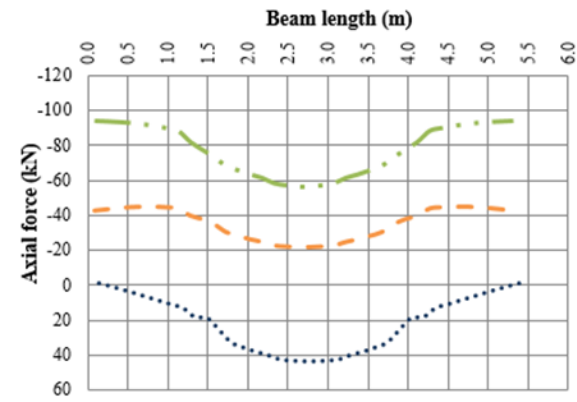

(a)

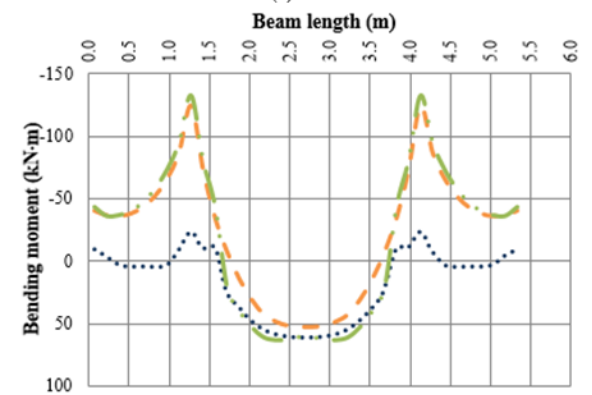

(c)

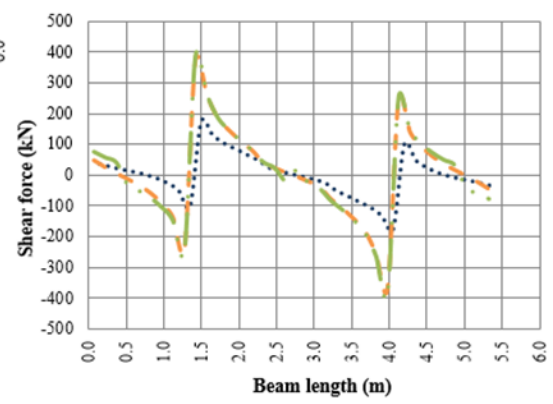

(b)

Beam length (m)

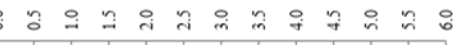

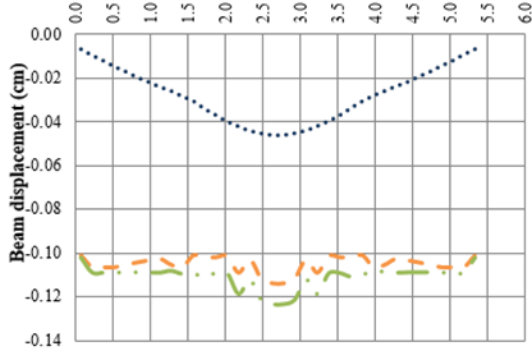

(d)

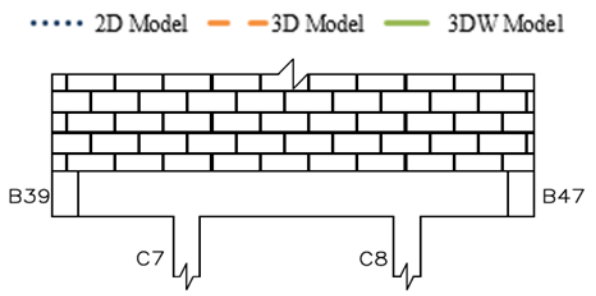

Figure 13. Forces on the support beam of Wall 3: (a) Axial force; (b) Shear force; (c) Bending moment; (d) Vertical displacement. 
The graphs of shear forces, illustrated in Figure 13b show the significant rise in the values obtained with the three-dimensional models, whose intensities resulted in more than twice the amount compared to the 2D model (Table 8). These differences may be attributed to normal stress distribution at the bottom of the wall, which represents vertical loading on the beam. According to the three-dimensional models, considerably higher normal stress intensities will increase shear forces in the same order of magnitude. It is also important to underscore that only the distribution of normal stresses outside the section of the column contributes to loading on the beam, not contributing to the maximum normal stress that occurs.

Table 8. Maximum forces and displacements in the support beam of Wall 3.

\begin{tabular}{|c|c|c|c|c|c|c|c|c|c|c|c|c|}
\hline \multirow{2}{*}{ Model } & \multicolumn{3}{|c|}{ Axial force $(\mathbf{k N})$} & \multicolumn{3}{|c|}{ Shear force $(\mathrm{kN})$} & \multicolumn{3}{|c|}{ Negative bending moment (kN.m) } & \multicolumn{3}{|c|}{ Displacements (cm) } \\
\hline & Maximum & $\Delta 2 \mathrm{D}$ & $\Delta 3 \mathrm{D}$ & $\overline{\text { Maximum }}$ & $\Delta 2 \mathrm{D}$ & $\overline{\Delta 3 \mathrm{D}}$ & Maximum & $\Delta 2 \mathrm{D}$ & $\overline{\Delta 3 \mathrm{D}}$ & Maximum & $\Delta$ 2D & $\Delta 3 \mathrm{D}$ \\
\hline $2 \mathrm{D}$ & 43.16 & - & - & 175.65 & - & - & 61.18 & - & - & 0.05 & - & - \\
\hline $3 \mathrm{D}$ & -45.11 & $105 \%$ & - & 373.63 & $113 \%$ & - & 124.89 & $104 \%$ & - & 0.11 & $120 \%$ & - \\
\hline 3DW & -94.02 & $218 \%$ & $108 \%$ & 388.91 & $121 \%$ & $4 \%$ & 132.41 & $116 \%$ & $6 \%$ & 0.12 & $140 \%$ & $9 \%$ \\
\hline
\end{tabular}

Figure 13d shows the significant differences in beam displacements of the three-dimensional models. This result may be due to the axial deformations of columns submitted to significantly higher axial forces, since the loading of interconnecting transverse walls are taken into account. Nevertheless, the absolute values obtained with all the models are very low and below the displacement limits prescribed in NBR 6118 [14], indicating that this aspect is not a complicating factor in the analysis of this type of structure.

With respect to bending moments, Figure $13 \mathrm{c}$ indicates significant increases only for negative bending moments, whose intensities are also more than double those of the 2D model (Table 8). Likewise, this can be explained by the distribution of normal stresses at the bottom of the wall, which exhibited considerable increases in the regions near the supports, thereby inducing greater changes in negative bending moments, with little influence on their positive counterparts. It is important to underscore that the increase in negative bending moments in the supports means this same type of moment occurs along the end spans of the beam, in contrast to the 2D model, where a positive bending moment is observed in these sections, albeit not intense. This substantially changes the design of this beam, with an increase in negative reinforcement and a longer span.

\subsubsection{Wall 41}

The results at the bottom of the wall in Figure 14a depict the distribution of normal stresses for the three models analyzed. At the two ends, the 2D model exhibited a more pronounced peak than those of the other models, where the 3D and 3VD models resulted in a 50\% decline in the region of column C7 (Table 9). In addition, at this same location, the $3 \mathrm{DW}$ model increased by $11 \%$ in relation to its $3 \mathrm{D}$ counterpart, highlighting the importance of considering the effects of wind in analysis. Column C7 is common to walls 41 and 3, and there is a tendency to overlap the normal stresses obtained with the respective planar models, whose values are presented in Tables 7 and 9. This overlapping resulted in a stress intensity of $13.83 \mathrm{MPa}, 2.4$ times greater than that obtained with the 3D model. Once again normal stresses were redistributed in the three-dimensional models which, in this case, resulted in a significant decline in maximum normal stress at the bottom of the wall. It is important to emphasize that this decrease was only possible due to the sections of masonry on the interconnecting transverse walls. Another important point refers to the links that promote this interconnection, which must provide sufficient strength to guarantee this redistribution. If this is not possible, redistribution will not be certain, and maximum stresses will increase, as observed in the results of the $2 \mathrm{D}$ model. This result underscores the need for 3D modeling in order to determine the interaction between the structural walls and transition structures of the building, as well as the importance of using procedures that guarantee the mobilization of limit forces in the connecting device capable of redistributing the stresses determined. However, in more central sections of the wall, the three-dimensional models exhibited slightly higher normal stresses than in the planar model, notably the localized peaks. This aspect characterizes behavior intrinsic to the wall-beam system, where the decline in maximum normal stresses in the region of support beams is accompanied by a rise in these stresses on the beam span. It is important to underscore that these increases were far lower than the significant declines at the ends of the wall. This corroborates the redistribution of stresses to the transverse walls, especially because the shorter span means the support beams of these walls are stiffer (Figure 4). 


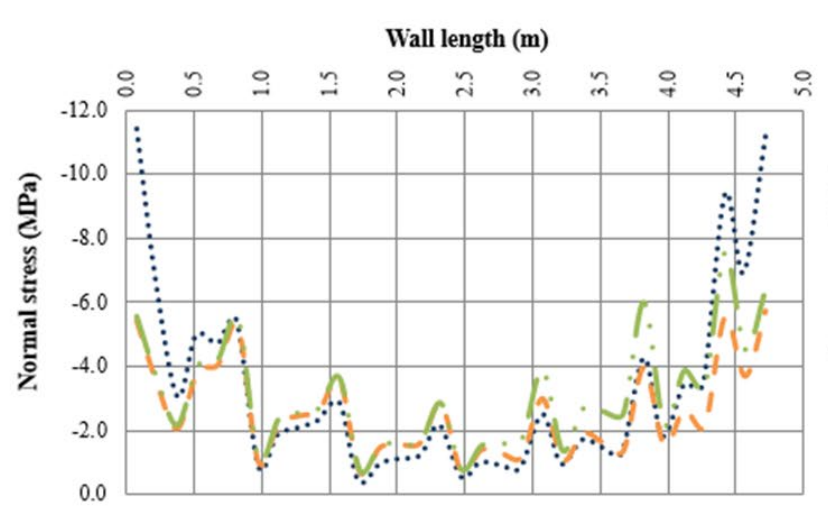

(a)

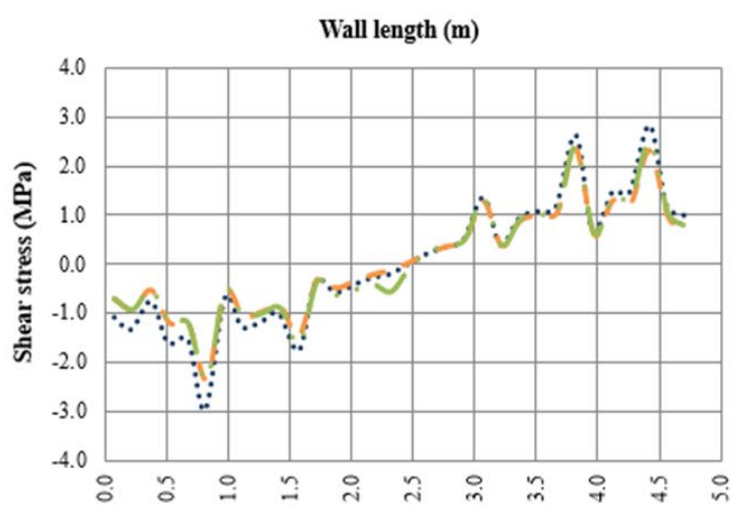

(b)

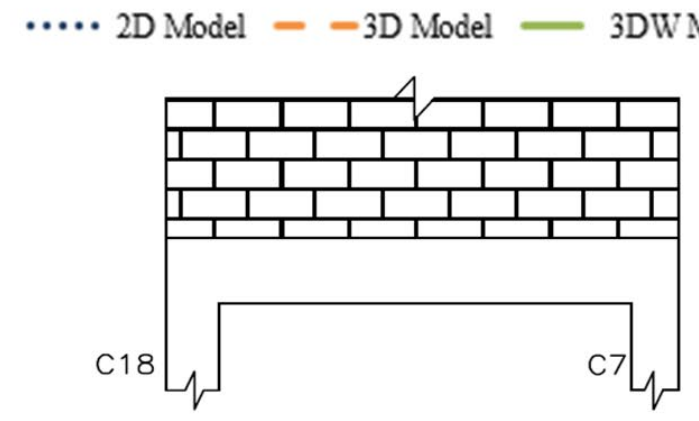

Figure 14. Stress distribution at the bottom of wall 41: (a) Normal stress; (b) Shear stress.

Table 9. Normal and shear stress at the bottom of Wall 41.

\begin{tabular}{|c|c|c|c|c|c|c|}
\hline \multirow{2}{*}{ Model } & \multicolumn{6}{|c|}{ Normal stress (MPa) - Maximum values } \\
\hline & Region C18 & $\Delta_{2 D}$ & $\Delta 3 \mathrm{D}$ & Region C7 & $\Delta_{2 D}$ & $\Delta 3 \mathrm{D}$ \\
\hline $2 \mathrm{D}$ & 11.4 & - & - & 11.17 & - & - \\
\hline $3 \mathrm{D}$ & 5.44 & $-52 \%$ & - & 5.75 & $-49 \%$ & - \\
\hline 3DW & 5.57 & $-51 \%$ & $2 \%$ & 6.40 & $-43 \%$ & $11 \%$ \\
\hline \multirow{2}{*}{ Model } & \multicolumn{6}{|c|}{ Shear stress (MPa) - Maximum values } \\
\hline & Region C18 & $\Delta 2 \mathrm{D}$ & $\Delta 3 \mathrm{D}$ & Region C7 & $\Delta 2 \mathrm{D}$ & $\Delta 3 \mathrm{D}$ \\
\hline $2 \mathrm{D}$ & 1.07 & - & - & 1.00 & - & - \\
\hline $3 \mathrm{D}$ & 0.70 & $-35 \%$ & - & 0.71 & $-29 \%$ & - \\
\hline $3 \mathrm{DW}$ & 0.70 & $-35 \%$ & $0 \%$ & 0.77 & $-23 \%$ & $8 \%$ \\
\hline
\end{tabular}

With respect to the shear stresses illustrated in Figure 14b, the intensities obtained with the 3D models tended to decline, albeit with slightly smaller differences (Table 9). As expected for this type of stress in wall-beam interaction, the maximum intensities did not occur at the ends of the walls, but in the internal sections.

The axial forces on the support beam illustrated in Figure 15a show that the three-dimensional models obtained higher values than in the planar model, of around $15 \%$ in the central region (Table 10). In contrast to what occurred in the support beam of wall 3, all the models indicated that tensile forces occurred along the entire beam. Another relevant point is the coincident location of the maximum axial force and the null shear stresses at the bottom of the wall, at the $2.5 \mathrm{~m}$ coordinate.

In regard to the shear force and bending moments, the 3D and 3DW models obtained lower maximum values than those of the 2D model, of around 9 and 15\%, respectively, as shown in Table 10. This greater difference in maximum positive bending moment was observed in the values of the other sections. This result is in line with the lower normal stress intensities at the bottom of the wall, near the columns, obtained with the 3D, as illustrated in Figure 14a.

In regard to displacements, illustrated in Figure 15d, the three-dimensional models displayed higher values than those of planar modeling. However, displacements at the ends, which correspond to axial deformation of the columns, were higher in the $3 \mathrm{D}$ models and if this difference was disregarded in the displacement diagram, the curves would be practically equal. 


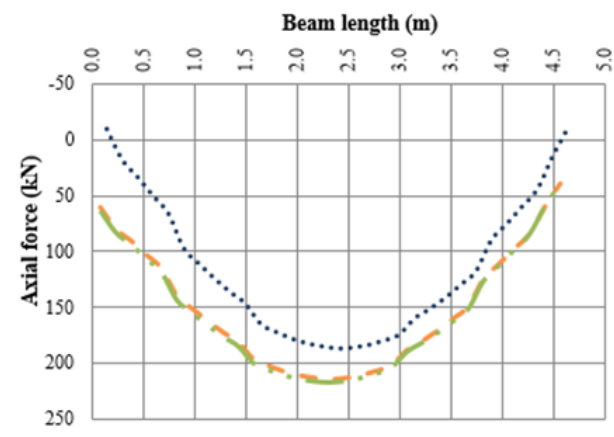

(a)

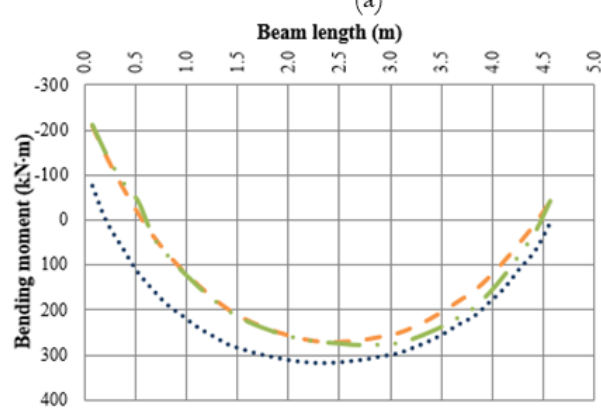

(c)

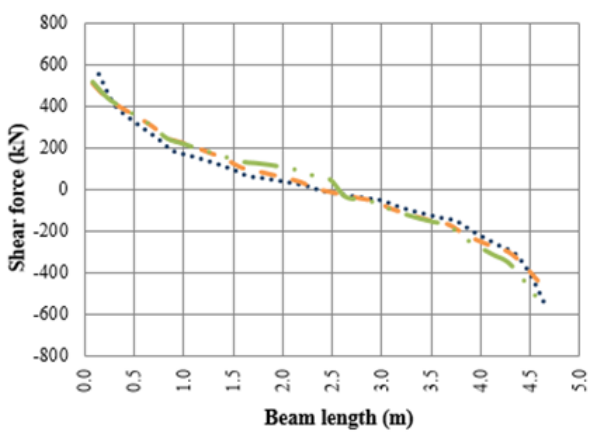

(b) Beam length (m)

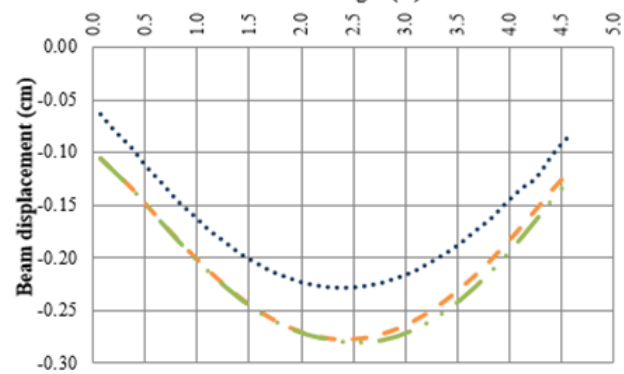

(d)

…2 2D Model $--3 \mathrm{D}$ Model - 3DW Model

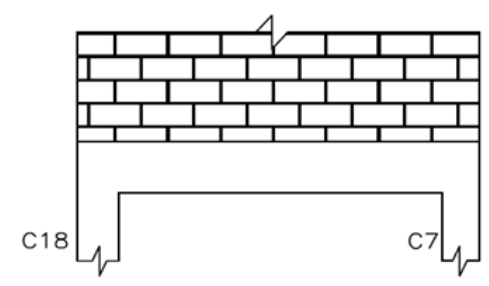

Figure 15. Forces on the support beam of wall 41: (a) Axial force; (b) Shear force; (c) Bending moment; (d) Vertical displacement.

Table 10. Maximum forces and displacements in the support beam of Wall 41 .

\begin{tabular}{|c|c|c|c|c|c|c|c|c|c|c|c|c|}
\hline \multirow{2}{*}{ Model } & \multicolumn{3}{|c|}{ Axial force (kN) } & \multicolumn{3}{|c|}{ Shear force $(k N)$} & \multicolumn{3}{|c|}{ Bending moment (kN.m) } & \multicolumn{3}{|c|}{ Displacements (cm) } \\
\hline & Maximum & $\Delta_{2 D}$ & $\Delta 3 \mathrm{D}$ & Maximum & $\Delta_{2 \mathrm{D}}$ & $\Delta_{3 \mathbf{D}}$ & Maximum & $\Delta_{2 D}$ & $\Delta 3 \mathrm{D}$ & Maximum & $\Delta_{2 D}$ & $\Delta_{3 D}$ \\
\hline $2 \mathrm{D}$ & 187.04 & - & - & 555.46 & - & - & 318.63 & - & - & 0.23 & - & - \\
\hline $3 \mathrm{D}$ & 214.56 & $15 \%$ & - & 505.54 & $-9 \%$ & - & 270.67 & $-15 \%$ & - & 0.28 & $22 \%$ & - \\
\hline $3 \mathrm{DW}$ & 216.23 & $16 \%$ & $1 \%$ & 525.97 & $-5 \%$ & $4 \%$ & 277.63 & $-13 \%$ & $3 \%$ & 0.28 & $22 \%$ & $0 \%$ \\
\hline
\end{tabular}

\subsection{Assessment of torsion and support beam design in reinforced concrete}

As described in item 3, after the structure was processed without considering eccentricity, the vertical forces for each frame at the bottom of the wall were multiplied by the corresponding eccentricity $-10.5 \mathrm{~cm}$ for walls 1,30 and 41 , and $8 \mathrm{~cm}$ for wall 3 -, in relation to the longitudinal support beam axis, in order to obtain the torsion load on the beam. Figure 16 illustrates the twisting moment applied, underscoring the higher intensities in the sections near the columns and the discontinuities corresponding to the dimensions of the respective transverse sections of the columns. This figure shows the complexity of this loading, which is intrinsic to the behavior of the wall-beam system itself, making its inclusion in simple manual calculation models impractical and demonstrating the need for computational analysis of the problem. 


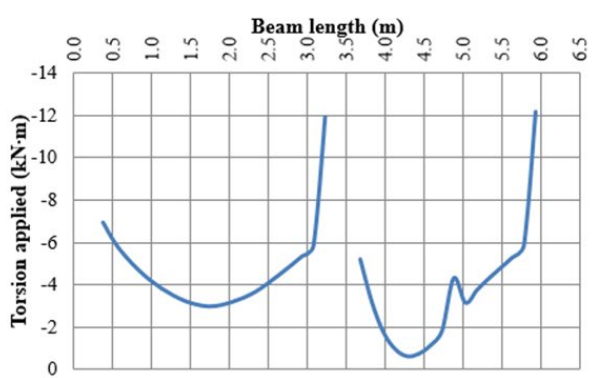

(a)

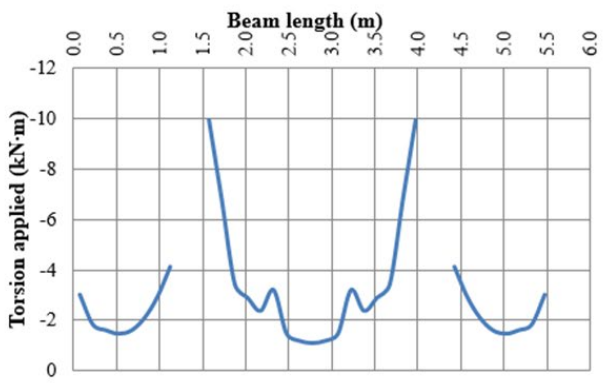

(c)

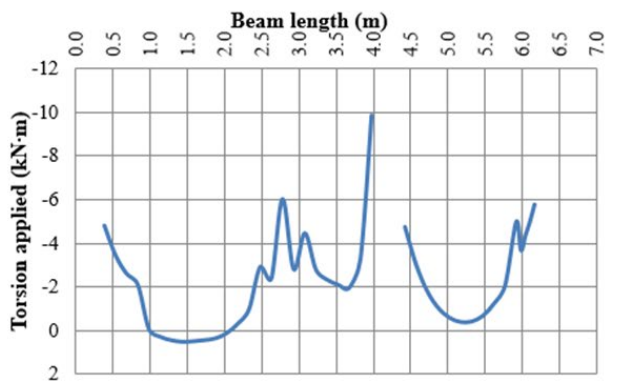

(b)

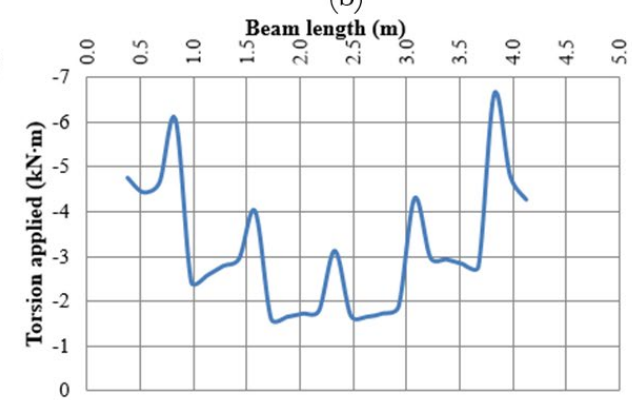

(d)

Figure 16. Torsion applied to reinforced concrete support beams without considering wind action: (a) Wall 1; (b) Wall 30; (c) Wall 3; (d) Wall 41.

Figure 17 illustrates the twisting moment diagrams of the planar and three-dimensional models for the four walls studied. The torsion compatibility values refer to the load applied without considering the twisting moments depicted in Figure 16, represent the reconciliation between the negative bending and twisting moments of the beams without regarding the eccentricity between the longitudinal axis and the vertical bars of the equivalent frame model. Figure 17 shows that including eccentric loading resulted in significant increases of maximum twisting moments, when compared to compatibility torsion. Likewise, the 3D and 3DW models exhibited similar values, but considerably different from the 2D model, except for wall 41 . The twisting moment applied to this wall was the least intense (Figure 16), which may explain the smaller difference.

Table 11 contains the maximum twisting moments acting on the beams, which increases when wall eccentricity is considered in relation to the longitudinal axis of the beam and when three-dimensional modeling of the structure is performed. Maximum intensities more than tripled when eccentricity was considered for beams B1 and B29. In the case of B40, the 25-fold increase in values is due to the non-occurrence of the twisting moment when eccentricity is not included, which, in turn, may be associated with the low intensity of the negative bending moments of beam B3. Even the lower increases in the twisting moment of 21 and 23\% in beam B3 could not be disregarded in the design.

Table 11. Intensities and maximum twisting moments in the support beams.

\begin{tabular}{|c|c|c|c|c|c|}
\hline \multirow{2}{*}{$\begin{array}{l}\text { WALL/ BEAM } \\
\text { (section) }\end{array}$} & \multirow{2}{*}{ MODEL } & \multicolumn{2}{|c|}{ MAXIMUM TWISTING MOMENT (kN·m) } & \multicolumn{2}{|c|}{ VARIATION } \\
\hline & & Disregarding eccentricity (1) & Considering eccentricity (2) & $\Delta_{(2)-(1)}$ & $\Delta_{\text {3D-2D }}$ \\
\hline \multirow{3}{*}{$\begin{array}{l}\text { W1/B1 } \\
(35 \times 80)\end{array}$} & $2 \mathrm{D}$ & -- & 38.39 & -- & -- \\
\hline & $3 \mathrm{D}$ & 13.91 & 51.09 & $267 \%$ & $33 \%$ \\
\hline & 3DW & 14.23 & 53.94 & $279 \%$ & $40 \%$ \\
\hline \multirow{3}{*}{$\begin{array}{l}\text { W30/B29 } \\
(35 \times 80)\end{array}$} & $2 \mathrm{D}$ & -- & 25.83 & -- & -- \\
\hline & $3 \mathrm{D}$ & 8.78 & 35.90 & $309 \%$ & $39 \%$ \\
\hline & 3DW & 14.31 & 41.36 & $189 \%$ & $60 \%$ \\
\hline \multirow{3}{*}{$\begin{array}{l}\mathrm{W} 3 / \mathrm{B} 3 \\
(30 \times 80)\end{array}$} & $2 \mathrm{D}$ & -- & 12.48 & -- & -- \\
\hline & $3 \mathrm{D}$ & 48.94 & 60.29 & $23 \%$ & $383 \%$ \\
\hline & 3DW & 54.38 & 65.70 & $21 \%$ & $426 \%$ \\
\hline \multirow{3}{*}{$\begin{array}{l}\text { W41/B40 } \\
(35 \times 80)\end{array}$} & $2 \mathrm{D}$ & -- & 63.06 & -- & -- \\
\hline & $3 \mathrm{D}$ & 2.02 & 56.33 & $2689 \%$ & $-11 \%$ \\
\hline & 3DW & 2.12 & 56.43 & $2562 \%$ & $-11 \%$ \\
\hline
\end{tabular}



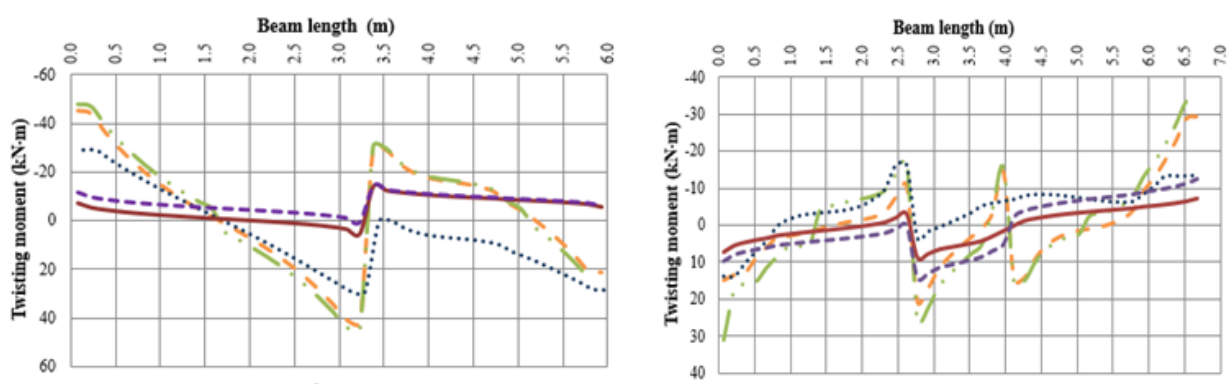

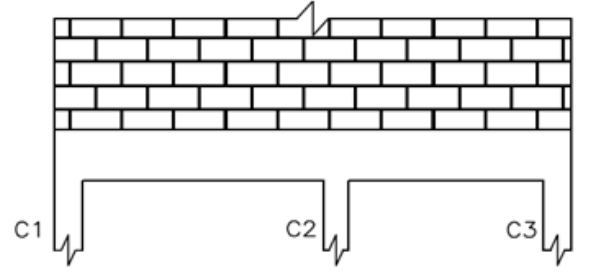

(a)
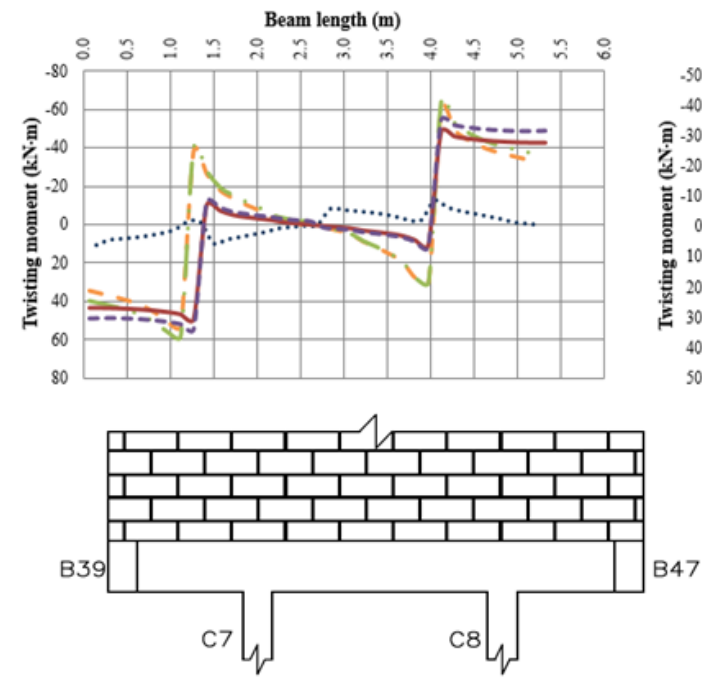

(c)

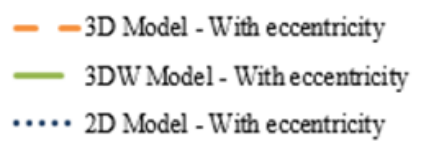

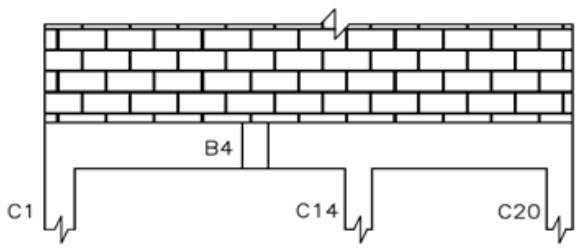

(b)
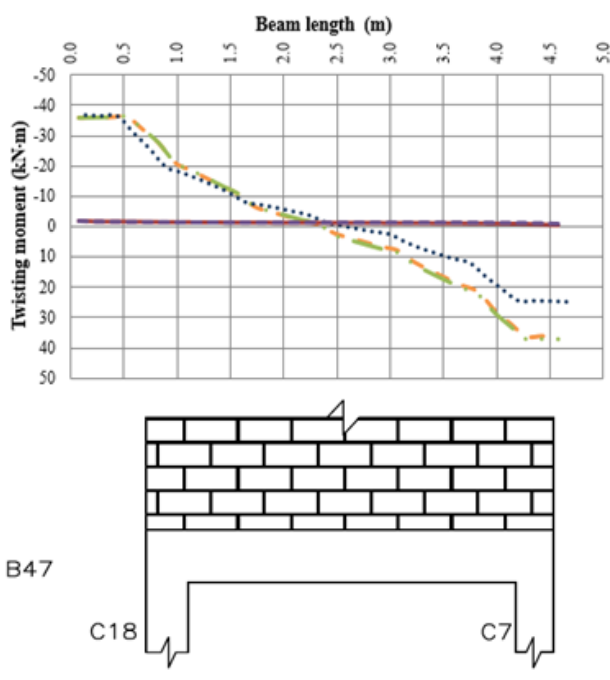

(d)

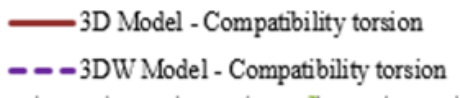

Figure 17. Twisting moments in reinforced concrete support beams: (a) Wall 1; (b) Wall 30; (c) Wall 3; (d) Wall 41.

Given the different types of modeling, except for beam B40, three-dimensional modeling resulted in increases in maximum twisting moments, notably in beam B3, whose intensity was multiplied by 4.83 and 5.26 in the models without and with the wind, respectively. By contrast, the maximum intensities of B40 declined by $11 \%$ in the two three-dimensional models. Both the significant increase in B3 and the reduction in B40 were due to the interaction between walls 3 and 41 in the three-dimensional model. This interaction relieves normal stresses at the bottom of wall 41 and substantially raises them at the bottom of wall 3 as a result of their redistribution in the 3D model, which is not included in the planar modeling of the walls, as observed in Figures $7 \mathrm{a}$.

Considering the twisting moments in Table 11, the normal stresses acting on the beams and the guidelines of NBR 6118 [14] regarding the design of beams submitted to simple bending and torsion, the corresponding designs were applied for the support beams, whose results are summarized in Table 12. Concrete with $f_{c k}=25 \mathrm{MPa}$ was used in the calculations and the distance from the center of gravity of the reinforcement to the face of the beam (d') was $3.5 \mathrm{~cm}$. 
Table 12 - Support beam design for vertical loading with and without eccentricity.

\begin{tabular}{|c|c|c|c|c|c|c|c|}
\hline \multirow{3}{*}{$\begin{array}{c}\text { Wall/ } \\
\text { Beam } \\
\text { (section) }\end{array}$} & \multirow{3}{*}{ Model } & \multicolumn{3}{|c|}{ Non-eccentric loading } & \multicolumn{3}{|c|}{ Eccentric loading } \\
\hline & & \multirow{2}{*}{$\begin{array}{c}\text { Long. Reinf. (flexo- } \\
\text { tensile + torsion) }\end{array}$} & \multicolumn{2}{|c|}{$\begin{array}{c}\text { Trans. Reinf. (shear force } \\
+ \text { torsion) }\end{array}$} & \multirow{2}{*}{$\begin{array}{c}\begin{array}{c}\text { Long. Reinf. (flexo- } \\
\text { tensile + torsion) }\end{array} \\
\text { As }\left(\mathrm{cm}^{2}\right)\end{array}$} & \multicolumn{2}{|c|}{$\begin{array}{c}\text { Trans. Reinf. (shear force } \\
+ \text { torsion) }\end{array}$} \\
\hline & & & Strut colapse & As $\left(\mathbf{c m}^{2}\right)$ & & Strut colapse & As $\left(\mathbf{c m}^{2}\right)$ \\
\hline \multirow{3}{*}{$\begin{array}{l}\mathrm{W} 1 / \mathrm{B} 1 \\
(35 \times 80)\end{array}$} & $2 \mathrm{D}$ & 8.07 & No & 11.67 & 15.38 & No & 14.85 \\
\hline & $3 \mathrm{D}$ & 11.24 & No & 16.14 & 18.00 & Yes & -- \\
\hline & 3DW & 12.81 & No & 18.58 & 19.56 & Yes & -- \\
\hline \multirow{3}{*}{$\begin{array}{l}\text { W30/B29 } \\
(35 \times 80)\end{array}$} & $2 \mathrm{D}$ & 8.05 & No & 10.92 & 12.97 & No & 13.06 \\
\hline & $3 \mathrm{D}$ & 13.13 & No & 20.87 & 18.27 & No & 22.49 \\
\hline & $3 \mathrm{DW}$ & 14.08 & No & 21.04 & 19.20 & Yes & -- \\
\hline \multirow{3}{*}{$\begin{array}{l}\text { W3/B3 } \\
(30 \times 80)\end{array}$} & $2 \mathrm{D}$ & 3.60 & No & 2.32 & 5.41 & No & 3.58 \\
\hline & $3 \mathrm{D}$ & 16.40 & Yes & -- & 18.69 & Yes & -- \\
\hline & 3DW & 17.95 & Yes & -- & 20.10 & Yes & -- \\
\hline \multirow{3}{*}{$\begin{array}{l}\text { W41/B40 } \\
(35 \times 80)\end{array}$} & $2 \mathrm{D}$ & 14.52 & No & 19.10 & 26.53 & Yes & -- \\
\hline & $3 \mathrm{D}$ & 12.58 & No & 16.93 & 22.65 & Yes & -- \\
\hline & $3 \mathrm{DW}$ & 12.96 & No & 17.89 & 22.86 & Yes & -- \\
\hline
\end{tabular}

Initial analysis showed non-compliance with the strut stress criterion in beam $\mathrm{B} 3$, for the 3D and 3DW models in the two loading situations, and in B1, for the 3DW model for eccentric loading, indicating the need to change the geometry of the section of these beams. Once again, this underscores the need to include wind action, vertical eccentric loads on the beam and three-dimensional modeling, given that both shear force and maximum twisting moment are far less intense with planar modeling, as shown in Figures $13 \mathrm{~b}$ and 17c. With respect to modeling conditions, the results of beam B3 should serve as a warning to masonry structure designers, who usually do not consider the effects of wall-beam eccentricity, typically using planar models when modeling wall-beam interaction.

Another relevant aspect of these results is the increase in horizontal reinforcement (bending-traction and torsion) in the three-dimensional models, initially due to non-eccentric loading. Differences of $51 \%$ were obtained for beam B29 and notably B3, where the amount of reinforcement was obtained with the 2D model multiplied by 2.9 and 3.1 for the $3 \mathrm{D}$ and 3DW models, respectively. This considerable increase in reinforcement in $\mathrm{B} 3$ underscores the high intensity of the forces obtained with three-dimensional modeling, corroborated by the fracture of struts. By contrast, horizontal reinforcement declined in B40, obtained with the three-dimensional models. Both results may be associated with stress redistribution between the walls, causing a significant rise in forces on B3 and a decline in B40.

Considerable increases were also observed in shear reinforcement. The results of beam B1 indicated differences of 38 and 59\% between the 3D and 3DW models, respectively, and the 2D model. In B29, the transverse reinforcement obtained from the 2D model was multiplied by 1.9 when determined using the forces obtained with the 3D and 3DW models. These increases in reinforcement may be due to stress redistribution between the walls, demonstrating the greater influence on shear behavior. Figure 18a shows this behavioral trend, underscoring the highest differences in beam B29.

Considering eccentric beam loading for cases where shear reinforcement can be determined, the results of beam B29 obtained 78.5 and $79.8 \%$ increases in transverse reinforcement with the 3D and 3DW models, respectively, in relation to the 2D model. For this same beam, longitudinal reinforcements 47.1 and $50.7 \%$ higher were obtained with the three-dimensional models, once again confirming the greater influence of stress redistribution on shear behavior, which can be explained by the high eccentricity values. If non-eccentric loading is considered, the trend remains unchanged, albeit with higher differences, as illustrated in Figures 18a and 18b. Compared to the change in modeling type adopted in analyses, this result indicates that including wall-beam eccentricity had a smaller impact on the increase in reinforcement. Likewise, Figure 19 demonstrates that incorporating eccentricity exerted greater influence on the increase in longitudinal reinforcements, as shown in the results of beams B1 and B40.

Given the brittle nature of the fracture for this type of load, this result is another example of the importance of three-dimensional modeling and considering the eccentricity between the structural wall axes and the support beam in the design of support beams. 


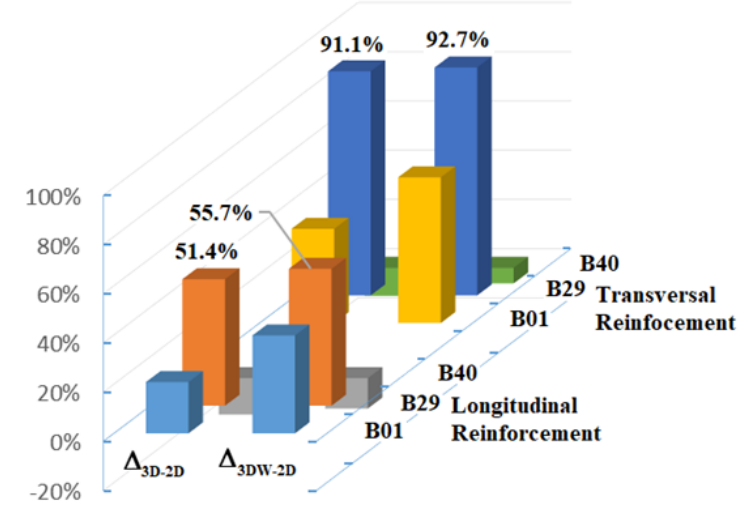

(a)

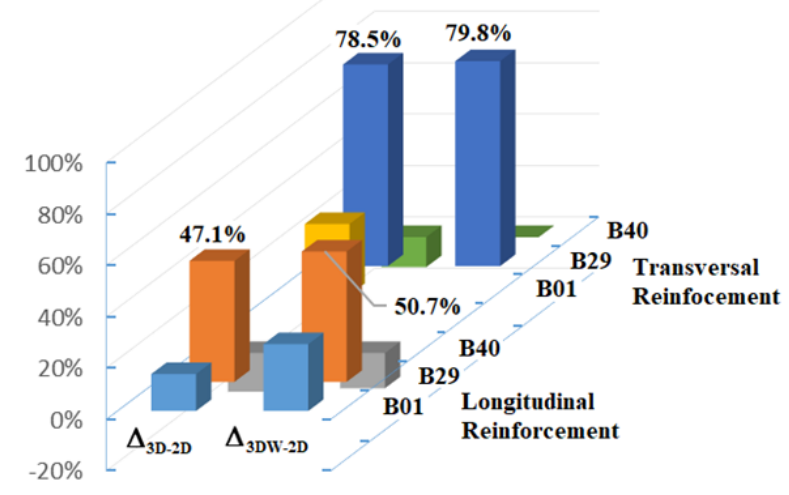

(b)

Figure 18. Differences between design results according to the analysis models: (a) Non-eccentric loading and (b) Eccentric loading.

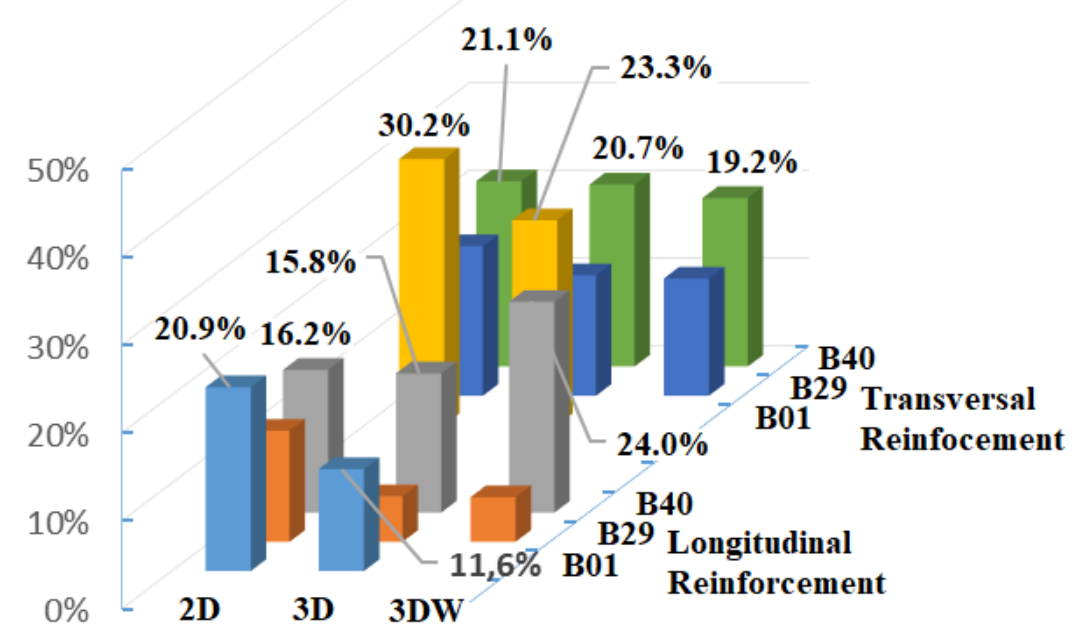

Figure 19. Difference between design results for eccentric and non-eccentric loading. 


\section{CONCLUSIONS}

The present study consisted of analyzing stress distribution in the structural walls of masonry buildings over a transition structure of reinforced concrete. Planar and three-dimensional modeling of the wall-beam system was performed, considering a possible eccentricity between the plane of the wall and the longitudinal axis of the beam. The analyses led to the following conclusions:

- A comparison between the planar and three-dimensional models confirmed the importance of interconnecting masonry walls, given that three-dimensional modeling revealed significant redistributions of normal vertical stresses at the bottom of the walls and shear stresses at the horizontal base joints, precluding planar modeling in the structural analysis of the wall-beam system in real situations. Overlapping the effects of planar models to determine the interconnection between wall proved to be inadequate;

- The stress redistribution observed in three-dimensional modeling resulted in significant changes in support beam forces, whose values were more than double those observed for the bending moment and shear force, reversing the direction of axial forces by changing from traction to compression;

- The flow of stresses to inside the wall is strongly influenced by openings in the masonry arranged near the columns of the support structure, and beam continuity, which can affect horizontal shear stress distribution at the bottom of the wall;

- The horizontal coordinate at the bottom of the wall, where horizontal shear stresses annul each other, corresponded to the cross-section of the beam, where axial force was either maximum or minimum;

- Wind action showed that both stresses at the bottom of the wall and forces on the support beams increased in intensity. The magnitude of the increases was influenced by different geometry and loading conditions. Thus, in order to ensure an adequate computational simulation of the wall-beam system, it is recommended that wind action always be taken into account;

- Calculating the torsion caused by eccentricity between the wall and the beam is no easy task and should be performed exclusively by computational modeling. The intensities obtained for the twisting moment indicated substantial increases in relation to those from the condition that does not consider this eccentricity;

- The effects caused by eccentric vertical loading in the studies conducted showed crushed struts in some of the beams analyzed, considering the criteria established in the Brazilian guideline. In addition, in cases where the necessary reinforcement was obtained, a considerable increase was observed in both longitudinal reinforcement, obtained for the combined effects of bending and torsion, and transverse reinforcement, obtained for the combined effects of shear force and twisting moment, demonstrating the need to include it in the design of support beams.

It is important to underscore that our findings correspond to the typology of the building selected for analysis, and should therefore not be generalized for any building. The results associated with the model that considers wind action cannot be extrapolated, for example, to low-rise buildings.

Finally, considering the guidelines of NBR 6118 [14] for the use of minimum shear reinforcement in order to prevent brittle fractures, the effects of wall-beam eccentricity should be carefully evaluated in the analysis of structural masonry buildings. If this analysis cannot be carried out, it is recommended that this eccentricity be eliminated to minimize torsion in the support concrete structure.

\section{REFERENCES}

[1] P. C. Barbosa, "Estudo da interação entre paredes de alvenaria estrutural com vigas de concreto armado," M.S. Dissertation, Esc. Eng. São Carlos, Univ. São Paulo, São Carlos, SP, 2000.

[2] M. S. Paes, "Interação entre edifício de alvenaria estrutural e pavimento em concreto armado considerando-se o efeito arco com a atuação de cargas verticais e ações horizontais,” M.S. Dissertation, Esc. Eng. São Carlos, Univ. São Paulo, São Carlos, SP, 2008.

[3] B. A. Haseltine and J. F. A. Moore, Handbook to BS-5628: Structural Use of Masonry. Part1: Unreinforced Masonry. Windsor, Berkshire: The Brick Development Association, 1981.

[4] J. A. Nascimento Neto., K. A. S. Medeiros, and F. Quim, "Nova modelagem para análise da interação entre painéis de alvenaria e estrutura de suporte," Rev. Prisma, no. 52, pp. 1-20, 2014.

[5] K. A. S. Medeiros, "Modelagem computacional para avaliação da interação entre painéis de alvenaria e estrutura de suporte em concreto armado,” M.S. Dissertation, Prog. Pós-grad. Eng. Civil, Univ. Fed. Rio Grande do Norte, Natal, RN, 2015.

[6] T. F. T. Silva, "Estudo da interação entre edifícios de alvenaria estrutural e pavimentos em concreto armado," M.S. Dissertation, Esc. Eng. São Carlos, Univ. São Paulo, São Carlos, SP, 2005. 
[7] J. G. Rots, "Numerical simulation of cracking in structural masonry," Heron, vol. 36, no. 2, pp. 49-63, 1991.

[8] P. B. Lourenço, “Computational strategies for masonry structures,” M.S. Dissertation, Delft Univ. Technol., Delft, 1996.

[9] O. G. Holanda Jr., "Influência de recalques em edifícios de alvenaria estrutural,” Ph.D. Thesis, Esc. Eng. São Carlos, Univ. São Paulo, São Carlos, SP, 2002.

[10] J. A. Nascimento Neto., "Estudo de painéis com abertura constituídos por alvenaria estrutural de blocos,” Ph.D. Thesis, Esc. Eng. São Carlos, Univ. São Paulo, São Carlos, SP, 2003.

[11] E. Testoni, “Análise estrutural de edifícios de paredes de concreto por meio de pórtico tridimensional sobre apoios elásticos,” M.S. Dissertation, Esc. Eng. São Carlos, Univ. São Paulo, São Carlos, SP, 2013.

[12] S. Rosenhaupt, "Experimental study of masonry walls on beams," J. Struct. Div., vol. 88, no. ST3, pp. 137-166, 1962.

[13] A. C. S. Lopes, "Aperfeiçoamento de modelagem computacional para análise da interação entre painéis de alvenaria e estrutura de suporte em concreto armado," Undergraduate Dissertation, Depart. Engenharia Civil, Univ. Fed. Rio Grande do Norte, Natal, RN, 2016.

[14] Associação Brasileira de Normas Técnicas, Projeto de Estruturas de Concreto - Procedimento, NBR 6118, 2014.

[15] Associação Brasileira de Normas Técnicas, Alvenaria Estrutural - Blocos de Concreto. Parte 1: Projeto, NBR 15961-1, 2011.

[16] G. A. Parsekian, A. A. Hamid, and R. G. Drysdale, Comportamento e Dimensionamento de Alvenaria Estrutural, 2nd ed. São Carlos: EdUFSCar, 2014.

[17] E. S. Fortes, "Influência do capeamento e caracterização da resistência à compressão de alvenaria estrutural de blocos de concreto," M.S. Dissertation, Prog. Pós-grad. Eng. Estrut. Constr. Civ., Univ. Fed. São Carlos, São Carlos, SP, 2012.

Author contributions: Anna Christinna Secundo Lopes: developed complementary computational modelling, elaborated some graphs, figures and results discussions, and also the whole manuscript; Joel Araújo do Nascimento Neto: supervisor of the main research as a master degree dissertation, elaborated some figures, results discussions and manuscript review; Klaus André de Sousa Medeiros: developed the main research as a master degree dissertation and reviewed some graphs and part of the manuscript; Daniel Nelson Maciel: contributed to the development of computational modelling in the main research, to the results discussions and to the manuscript review.

Editors: Osvaldo Luís Manzoli, José Luiz Antunes de Oliveira e Sousa, Guilherme Aris Parsekian. 